\title{
A GC-FID-Based Method for Quantifying the Breakdown of TIDG in NGS Solvent
}

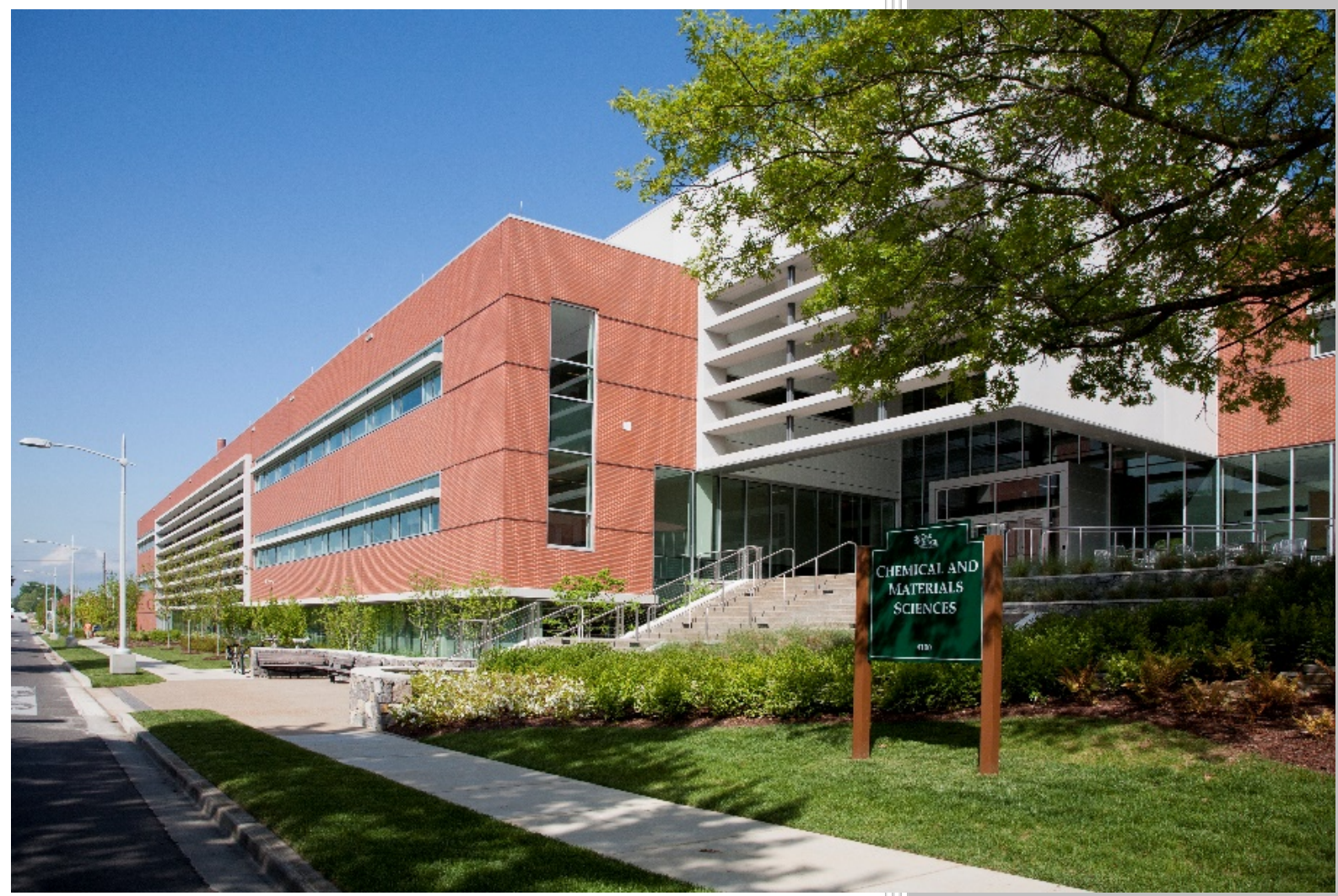

Frederick V. Sloop, Jr.

Approved for public release.

Distribution is unlimited.
September 2018 


\section{DOCUMENT AVAILABILITY}

Reports produced after January 1, 1996, are generally available free via US Department of Energy (DOE) SciTech Connect.

Website www.osti.gov

Reports produced before January 1, 1996, may be purchased by members of the public from the following source:

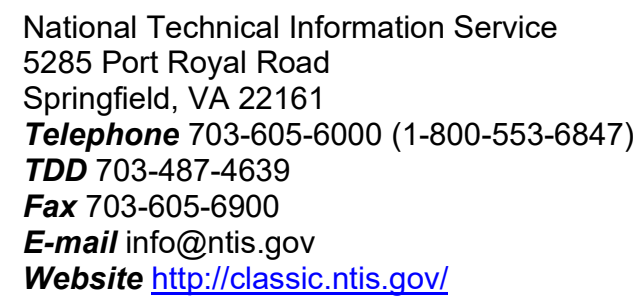

Reports are available to DOE employees, DOE contractors, Energy Technology Data Exchange representatives, and International Nuclear Information System representatives from the following source:

Office of Scientific and Technical Information

PO Box 62

Oak Ridge, TN 37831

Telephone 865-576-8401

Fax 865-576-5728

E-mail reports@osti.gov

Website http://www.osti.gov/contact.html

This report was prepared as an account of work sponsored by an agency of the United States Government. Neither the United States Government nor any agency thereof, nor any of their employees, makes any warranty, express or implied, or assumes any legal liability or responsibility for the accuracy, completeness, or usefulness of any information, apparatus, product, or process disclosed, or represents that its use would not infringe privately owned rights. Reference herein to any specific commercial product, process, or service by trade name, trademark, manufacturer, or otherwise, does not necessarily constitute or imply its endorsement, recommendation, or favoring by the United States Government or any agency thereof. The views and opinions of authors expressed herein do not necessarily state or reflect those of the United States Government or any agency thereof. 
Chemical Sciences Division

\title{
A GC-FID-Based Method for Quantifying the Breakdown of TiDG in NGS Solvent
}

\author{
Frederick V. Sloop, Jr.
}

Date Published: September 2018

Prepared by

OAK RIDGE NATIONAL LABORATORY

Oak Ridge, TN 37831-6283

managed by

UT-BATTELLE, LLC

for the

US DEPARTMENT OF ENERGY

under contract DE-AC05-00OR22725 



\section{CONTENTS}

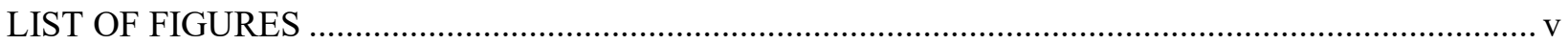

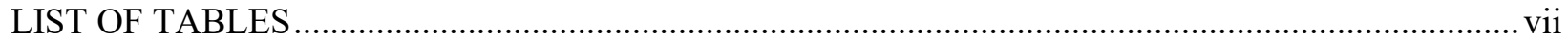

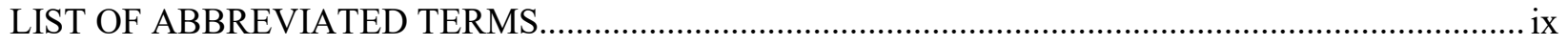

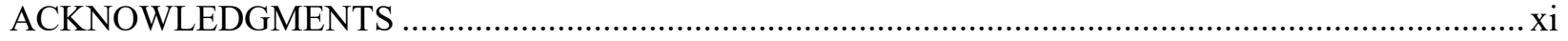

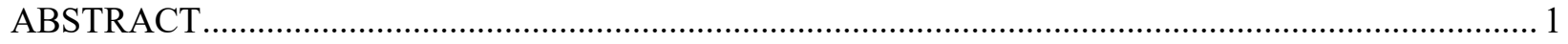

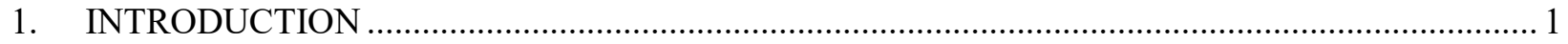

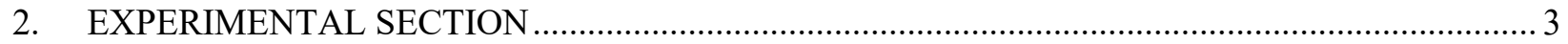

2.1 SOLVENT AND DEGRADED GUANIDINE COMPOSITIONS …................................. 3

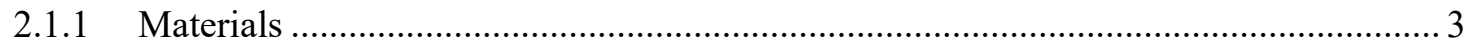

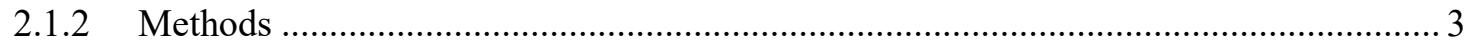

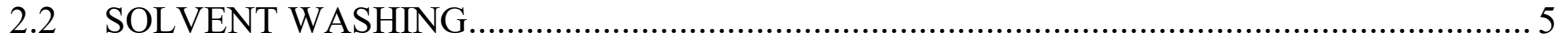

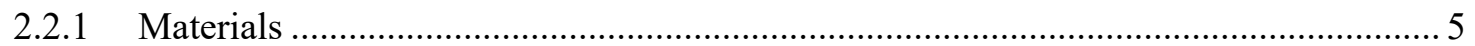

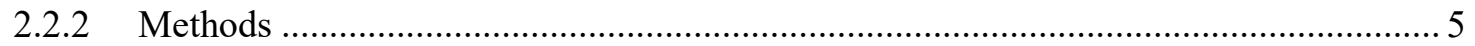

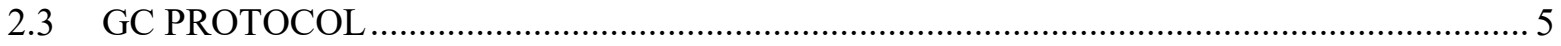

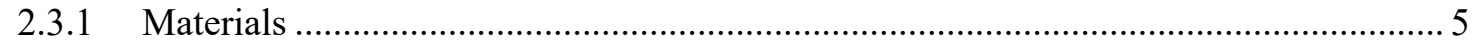

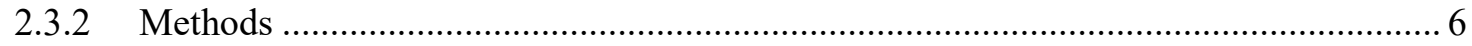

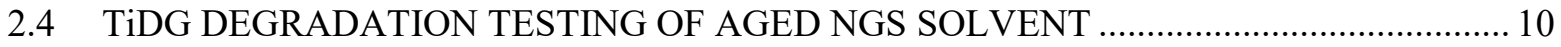

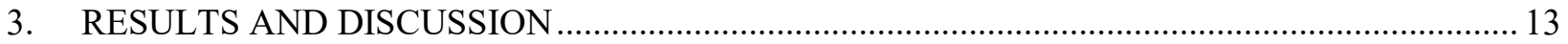

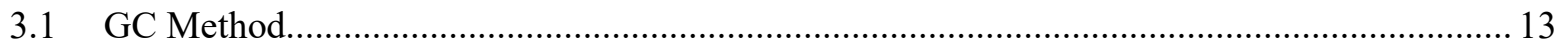

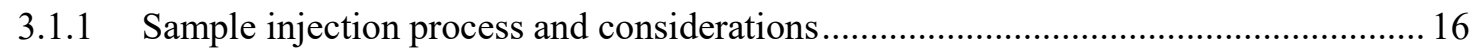

3.2 TESTING ABILITY OF THE GK COLUMN AND THE NSG-GUA 1.M METHOD

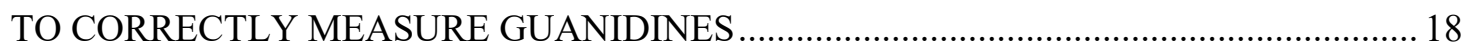

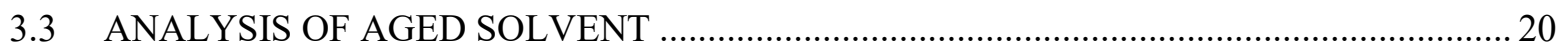

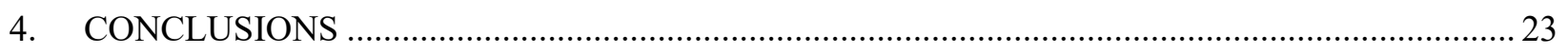

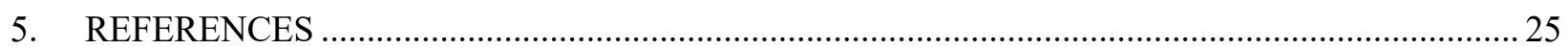

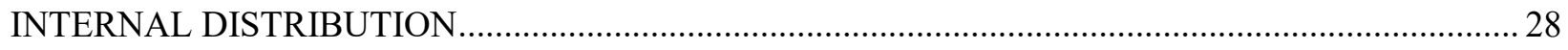

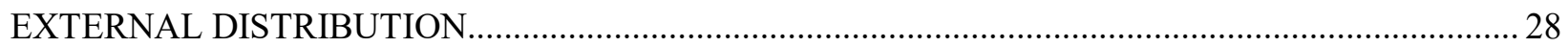




\section{LIST OF FIGURES}

Figure 2.1 Calibration Tables \& Curves for di-iDU and TiDG - column 1 (Agilent J\&W CP8907 GC)

Figure 2.2 Calibration Tables \& Curves for di-iDU and TiDG - column 2 (GS-Tek GsBP-1MS). 10

Fig. 3.1 Chromatogram obtained using GC method NGS-Gua1.M showing well-separated peaks

of TiDG, di-iDU, and iDA in the absence of Isopar-L, MaxCalix and Cs-7SB.

Fig. 3.2 Chromatogram showing 1:10 dilution of Isopar in DCM........................................................ 14

Fig. 3.3 Chromatogram of 1:10 dilution of $0.5 \mathrm{M}$ Cs-7SB in DCM ................................................... 14

Fig. 3.4. Chromatogram of 1:20 dilution of $50 \mathrm{mM}$ MaxCalix in Isopar diluted in DCM....................... 14

Fig. 3.5 Chromatogram of 1:10 dilution (in DCM) of Full NGS Solvent also containing $3 \mathrm{mM}$ diIsodecylurea

Fig. 3.6 GC Chromatograms of Various Solvent Components - Individually \& in Combination

Fig. 3.7 Calibration curve of TiDG in DCM obtained using method NGS-Gua1.M-Column 2.

Fig. 3.8 Calibration curve of di-iDU in DCM obtained using method NGS-Gua1.M-Column 2 ............. 18

Fig. 3.9. Various GC Chromatograms of TiDG and di-iDU Mixtures in $0.5 \mathrm{M}$ Cs7SB/IsoparDiluted 1:5 in DCM

Figure 3.10. Chromatograms Showing CG-FID peaks of TiDG and di-iDU in washed and unwashed NGS Solvent stored at either $25^{\circ} \mathrm{C}$ or $35^{\circ} \mathrm{C}$ for 19 months 


\section{LIST OF TABLES}

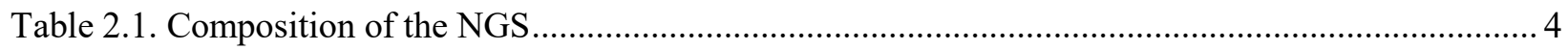

Table 2.2. Parent TiDG Guanidine and its Degradation Products ........................................................ 4

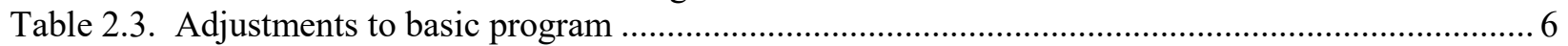

Table 2.4. Program (NGS-Gua1.M) established for TiDG breakdown products analysis......................... 7

Table 2.5 Serial dilutions of stock $3 \mathrm{mM}$ TiDG for standard curve ........................................................ 8

Table 2.6 Serial dilutions of stock $3 \mathrm{mM}$ di-isodecylurea for standard curve ......................................... 8

Table 2.7 Serial dilutions of stock $3 \mathrm{mM}$ 3,7-dimethyloctan-1-amine for standard curve ....................... 9

Table 3.1. Program (NGS-Gua1.M) established for TiDG breakdown products analysis........................ 16

Table 3.2. Dilution Series for GC Standard Curve for 1:5 dil. of $3.0 \mathrm{mM}$ TiDG, ................................. 18

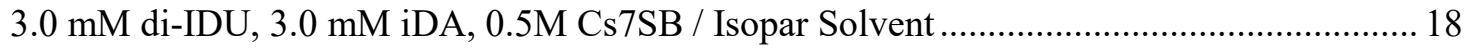

Table 3.3. Peak Area Data for Testing GC Standard Curves to Correctly Calculate Various Concentrations of TiDG and di-IDU in 0.5M Cs7SB / Isopar Diluted 1:5 in DCM ............... 20

Table 3.4. GC determination of degradation of TiDG in stored* NGS solvent....................................... 21 


\section{LIST OF ABBREVIATED TERMS}

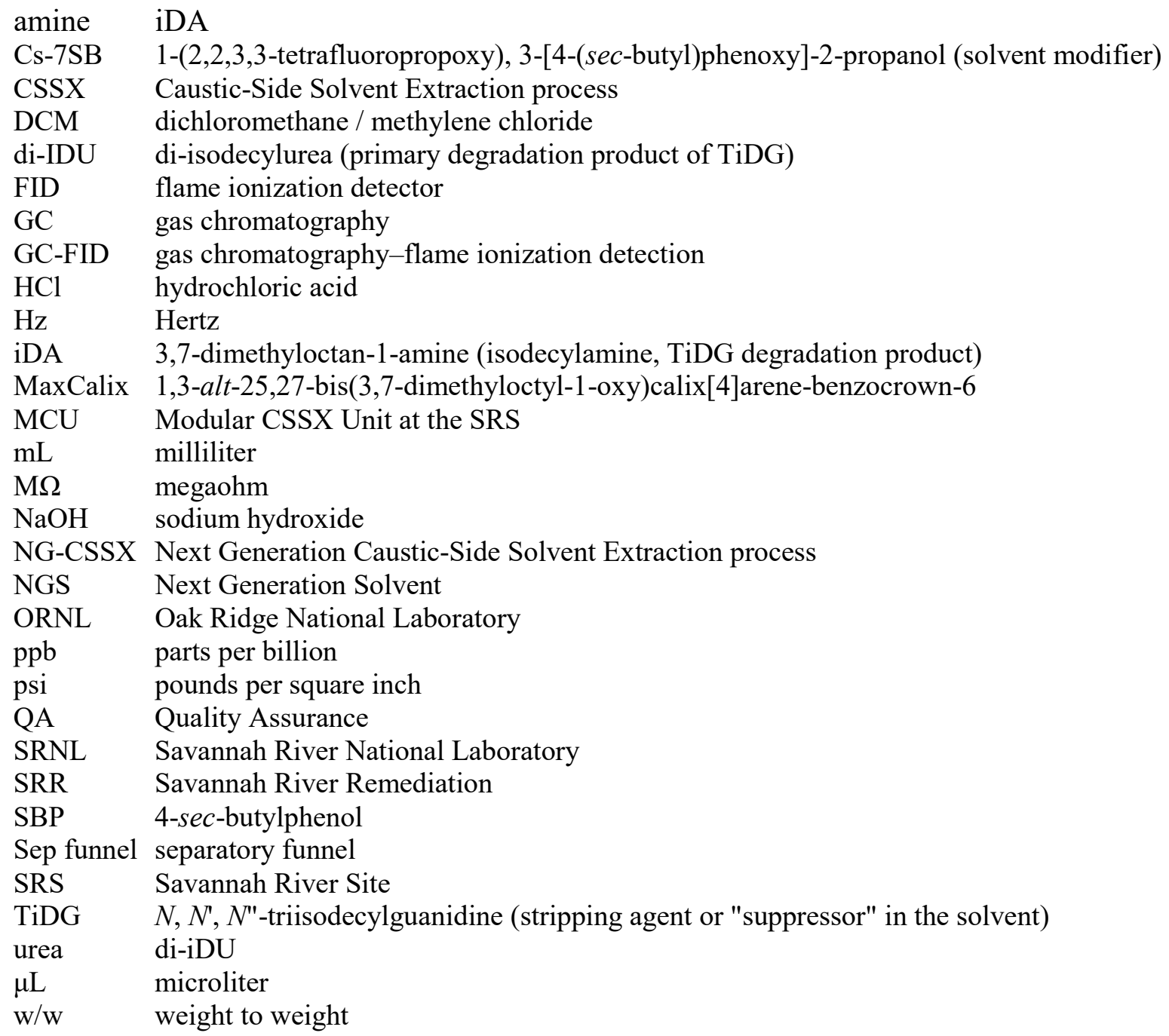




\section{ACKNOWLEDGMENTS}

Thanks to Ben Roach for sharing samples from his long-term guanidine degradation study (TiDG in NGS solvent) and for his ESI-MS data showing iDA concentrations in NGS solvent after 19 months. This research was sponsored by the Office of Technology Innovation and Development, Office of Environmental Management, U.S. Department of Energy. 


\begin{abstract}
A fast and reliable analytical technique for monitoring the levels of the Next Generation Solvent (NGS) solvent suppressor, $N, N^{\prime}, N^{\prime}$--tris(3,7-dimethyloctyl)guanidine (TiDG), is required due to the susceptibility of this guanidine to degradation arising from the thermal and chemical conditions encountered in the Next Generation Caustic-Side Solvent Extraction (NG-CSSX) process currently in use at the Savannah River Site. This report documents the development of a GC-FID-based (Gas Chromatography-Flame Ionization Detection) technique for analyzing and quantifying TiDG and its primary degradation product, diisodecylurea (di-iDU), as a means of near real-time surveillance of the NGS solvent. Upon experimental certification, the technique was subsequently utilized to measure the degradation of this suppressor component of the NGS solvent following a storage period of 19 months at both $25^{\circ} \mathrm{C}$ and $35^{\circ} \mathrm{C}$.

As currently described, this simple technique can be used to monitor the amounts of both TiDG and diiDU in NGS solvent in less than 15 minutes time, thus offering near real-time guidance as to the levels of suppressor and its primary degradation product. This analytical information is essential for calculating the quantity of TiDG that must be routinely added to the solvent under conditions of continual suppressor degradation, in order to maintain stripping performance.
\end{abstract}

\title{
1. INTRODUCTION
}

To suppress the deleterious effect of rogue anions on stripping, a lipophilic organic base called the "suppressor" is added to the solvent used in radio-cesium extraction at the Savannah River Site (SRS). ${ }^{1}$

In the original process, Caustic-Side Solvent Extraction (CSSX), the suppressor was tri- $n$-octylamine (TOA) ${ }^{2-3}$ while in NG-CSSX, the suppressor is a guanidine. Initially, the guanidine employed in NGS was $N, N^{\prime}$-dicyclohexyl- $N^{\prime \prime}$-isotridecylguanidine (DCiTG), ${ }^{4-9}$ but its modest loss to the aqueous stripping solution led to a switch to the more lipophilic guanidine $N, N^{\prime}, N^{\prime \prime}$-tris(3,7-dimethyloctyl)guanidine (TiDG) ${ }^{10,11}$ While this increase in lipophilicity solved the problem of loss to the aqueous strip, a new issue, the slow degradation of the base due to thermal stress, became apparent. ${ }^{12,13}$ This decomposition reduces the concentration of TiDG in the solvent and leads to a build-up of two breakdown products, di-isodecylurea (di-iDU) and 3,7-dimethyloctan-1-amine (isodecylamine) (iDA). While the amine (iDA) is expected to wash out of the solvent, the highly soluble urea (di-iDU) might remain and build-up over time, leading to unknown effects on the process. ${ }^{12,13}$ Until a more stable suppressor molecule can be developed, it will be necessary to add TiDG to the NGS solvent as needed. To know when and how much suppressor must be added to replenish that which has been degraded, it has become necessary to monitor the level of TiDG in the solvent on a continual basis.

This report describes the development of a simple gas-chromatography (GC) based method for quantifying TiDG and one of its degradation products, di-iDU, that might build-up in the solvent over time. In order to quantify the second degradation product, iDA, it must be extracted from the solvent prior to GC analysis due to the masking effect of Isopar. This is an unnecessary complicating factor, since this amine is expected to wash out of the solvent. Therefore, only TiDG and di-iDU will be analyzed using this protocol.

In this newly developed analytical method, the solvent sample is introduced via syringe injection onto a GC column. The various solvent sample components interact differentially with the column's stationary phase according to their chemical and physical properties as they are swept along by a gaseous hydrogen mobile phase. Upon exiting the column, the analyte molecules are detected using an FID (flame ionization detector) in which a hydrogen-fueled flame pyrolyzes organics to form cations and electrons, which then generate a current when they pass between a pair of electrodes. This current appears as a peak or peaks on a chromatogram that is assigned an identity based upon known molecular behaviors. 
This analytical method was developed in a step-wise fashion by first utilizing dichloromethane (DCM) solvent to make individual solutions of TiDG, di-iDU, (urea) or iDA (amine) in order to fix their locations in the chromatograph. The same approach was taken to fix the locales of Isopar, Cs-7SB, and MaxCalix. Full NGS solvent was then spiked with either urea or amine to eventually fix and otherwise identify all peaks appearing in the chromatograph to reflect real-world conditions and applications.

A suitable column was selected through consideration of the chemical nature of the target analytes. It was considered that the column used for 4-sec-butylphenol quantification, ${ }^{14}$ an Agilent J\&W CP8907 VF$1 \mathrm{MS}, 100 \%$ dimethyl polysiloxane, measuring 15 meters long $\times 0.25 \mathrm{~mm}$ ID $\times 0.25 \mu \mathrm{m}$ film thickness, would be a good candidate for guanidines, ureas, and amines. A second column, with the same physical and chemical characteristics, but from a different vendor (General Separations Technologies, Inc., GS-Tek GsBP-1MS), was also tested. These low-polarity columns are highly dispersive and rapidly elute the hydrocarbon solvent, holding up other components for longer retention times, allowing for good separation of the guanidine and its urea and amine degradation products.

The starting hardware settings (including pressures, $\mathrm{H}_{2}$ and air flow rates, velocities, oven temperatures over time, event times, detector temperature, and other settings) were approximately the same as those used for 4-sec-butylphenol analysis. Parameters were then systematically changed from initial conditions to positively influence the analyte positions in the resulting chromatograms.

Once appropriate analytical conditions were achieved, serial dilutions were made for TiDG and its urea degradation product using DCM. The dilution series were used to generate standard curves for TiDG and di-iDU, thus permitting the quantification of those components in test samples.

The analytical technique was validated by injecting various test solvent samples containing different amounts and ratios of TiDG and di-iDU, while using the standard curves to solve for their concentrations.

Once developed and validated, the GC-FID-based method was used to analyze the degree of TiDG degradation in full NGS solvent that was either washed or unwashed, and stored at either $25{ }^{\circ} \mathrm{C}$ or $35^{\circ} \mathrm{C}$ for a period of 19 months. 


\section{EXPERIMENTAL SECTION}

\subsection{SOLVENT AND DEGRADED GUANIDINE COMPOSITIONS}

\subsubsection{Materials}

Solvent and suppressor breakdown components were obtained from commercial sources or synthesized in-house and judged to be of adequate purity for use as received. 1-(2,2,3,3-Tetrafluoropropoxy),3-[4-(secbutyl)phenoxy]-2-propanol (Cs-7SB modifier, Lot No. MOD2012-M-1), 1,3-alt-25,27-bis(3,7dimethyloctyl-1-oxy)calix[4] arene-benzocrown-6 (MaxCalix, Lot No. 79-008-1), and the guanidine suppressor $N, N^{\prime}, N^{\prime}$-tris(3,7-dimethyloctyl)guanidine in the form of its $\mathrm{HCl}$ salt (TiDG, Lot No. 79-221-1), were all obtained from Marshallton Research. Isopar L, Lot No. US67377E was obtained from ExxonMobil. TiDG breakdown component 3,7-dimethyloctan-1-amine (lot no. PB-CSG-2010-8-1, isodecylamine, iDA) was synthesized in-house by P. V. Bonnesen, while di-isodecylurea (di-iDU, lot no. NJW-20Feb15) was similarly synthesized by N. J. Williams.

Water for preparation of all aqueous solutions was deionized using a Milli-Q ${ }^{\circledR}$ gradient A10 filtering system equipped with a Quantum ${ }^{\mathrm{TM}}$ Ex Ultrapure Organex Cartridge $\left(18.2 \mathrm{M} \Omega \bullet^{\bullet} \mathrm{cm}\right.$ at $25^{\circ} \mathrm{C}$, total organic content $4 \mathrm{ppb}$ ).

Appropriate amounts of the various components were weighed using an ORNL Metrology-calibrated Ohaus AR2140 Adventurer balance, along with a calibrated set of check weights that was used both prior to and immediately after using the balance to weigh solvent components. Comparisons of balance readings were made using both $1.0000 \mathrm{~g}$ and $10.0000 \mathrm{~g}$ check weights. Appropriate liquid volumes were achieved using volumetric glassware and/or ORNL Metrology calibrated Eppendorf pipettes.

\subsubsection{Methods}

Full solvent was prepared by weighing appropriate amounts of extractant, modifier, and suppressor into volumetric flasks and diluting with Isopar L to the mark. Assuming 100\% purity of as-received solvent components, the actual concentrations for NGS are shown in Table 2.1. The NGS used in this method development exercise was $0.050 \mathrm{M}$ MaxCalix, $0.50 \mathrm{M} \mathrm{Cs-7SB}$, and $0.003 \mathrm{M}$ TiDG in Isopar L diluent. This formulation has been in use in the MCU since 2014. ${ }^{11}$ A second simpler basic solvent, lacking MaxCalix, was also prepared after it became apparent the extractant, due to its large size and lack of volatility at the instrument temperatures encountered, would 'hang up' on the GC's injector. This solvent was used for the creation of the GC standard curves necessary for quantifying of TiDG and di-iDU and validating the analytical technique.

After mixing, the complete solvent was washed by sequential contacts of equal volumes of 0.010 $\mathrm{M} \mathrm{HCl}, \mathrm{H}_{2} \mathrm{O}$, then by decreasing concentrations of $\mathrm{NaOH}(0.3 \mathrm{M}, 0.1 \mathrm{M}, 0.03 \mathrm{M}$, and $0.01 \mathrm{M})$, and finally with $\mathrm{H}_{2} \mathrm{O}$ until the solution was $\mathrm{pH}$ neutral. This washing protocol was adopted from methodology used in the development of the CSSX process in which minor impurities in as-received solvent components were removed by washing with the $\mathrm{HCl}$ and $\mathrm{NaOH}$ solutions respectively. ${ }^{1}$

For initial testing, a 1mM TiDG, $1 \mathrm{mM}$ di-iDU, and 1mM iDA-spiked Simple Solvent (Table 2.2) was prepared which consisted of $0.50 \mathrm{M}$ Cs-7SB in Isopar L. Test solutions were also formulated containing differing concentrations of the individual TiDG, di-iDU, and iDA components (Tables 2.3, 2.4, 2.5) in DCM for establishing standard curves on the GC-FID. 
Table 2.1. Composition of the NGS

\begin{tabular}{|c|c|c|}
\hline Compound & $\begin{array}{l}\text { Molecular } \\
\text { Weight } \\
(\mathrm{g} / \mathrm{mol}) \\
\end{array}$ & $\begin{array}{c}\text { Actual } \\
\text { Concentration } \\
(\mathrm{mol} / \mathrm{L})\end{array}$ \\
\hline $\begin{array}{c}\text { 1,3-alt-25,27-Bis }(3,7- \\
\text { dimethyloctyl-1-oxy)calix[4]arene- } \\
\text { benzocrown-6 } \\
0.050 \text { M MaxCalix }\end{array}$ & 955.435 & 0.050 \\
\hline $\begin{array}{l}\text { 1-(2,2,3,3-Tetrafluoropropoxy)-3- } \\
\text { (4-sec-butylphenoxy)-2-propanol } \\
\quad 0.50 \mathrm{M} \mathrm{Cs-7SB}\end{array}$ & 338.37 & 0.50 \\
\hline $\begin{array}{c}N, N^{\prime}, N^{\prime},- \text { Tris }(3,7- \\
\text { dimethyloctyl)guanidine } \\
0.003 \text { M TiDG }\end{array}$ & $\begin{array}{l}516.39 \\
\text { as } \mathrm{HCl} \\
\text { form }\end{array}$ & 0.003 \\
\hline $\mathrm{C}_{12}$ isoparaffinic hy & & \\
\hline \multirow{2}{*}{\multicolumn{3}{|c|}{$\begin{array}{l}\text { * This table previously appeared in ORNL/TM-2014/444, Using GC-FID to quantify the removal of 4-sec- } \\
\text { Butylphenol from NGS solvent by NaOH. }{ }^{14}\end{array}$}} \\
\hline & & \\
\hline Compound & \multicolumn{2}{|c|}{ Physical Information } \\
\hline $\begin{array}{c}N, N^{\prime}, N^{\prime} \text {-Tris }(3,7- \\
\text { dimethyloctyl)guanidine } \\
\text { TiDG }\end{array}$ & \multicolumn{2}{|c|}{$\begin{array}{l}\mathrm{mw}=479.89(516.39 \text { as the } \mathrm{HCl} \\
\text { form }) \text { Marshallton, lot } \# 79-179-1\end{array}$} \\
\hline $\begin{array}{l}\text { di-isodecylurea } \\
\text { di-iDU }\end{array}$ & $\begin{array}{l}\mathrm{C}_{21} \mathrm{H}_{44} \mathrm{~N}_{2} \mathrm{O}, \mathrm{fw}=3 \\
\text { Synthesized by Ne } \\
\text { NJW-20Feb15 }\end{array}$ & $\begin{array}{l}0.59 \\
\text { Williams }\end{array}$ \\
\hline $\begin{array}{l}\text { 3,7-dimethyloctan-1- } \\
\text { amine } \\
\text { iDA }\end{array}$ & \multicolumn{2}{|c|}{$\begin{array}{l}\mathrm{C}_{10} \mathrm{H}_{23} \mathrm{~N} ; \mathrm{mw}=157.30,2 \mathrm{x} \text { distilled } \\
\text { Synthesized by P. Bonnesen } \\
\text { PB-CSG-2010-8-1 }\end{array}$} \\
\hline
\end{tabular}




\subsection{SOLVENT WASHING}

\subsubsection{Materials}

A $50 \% \mathrm{NaOH}(\mathrm{w} / \mathrm{w})$ solution, was obtained from JT Baker. Concentrated hydrochloric acid, GR, was obtained from EM Science.

Washing solutions were prepared through appropriate dilutions of commercial $50 \% \mathrm{NaOH}$ and concentrated $\mathrm{HCl}$ using distilled deionized $18.2 \mathrm{M} \Omega \bullet \mathrm{cm}$ water. The solutions prepared included $0.01 \mathrm{M}$ $\mathrm{HCl}$ and $0.30 \mathrm{M}, 0.10 \mathrm{M}, 0.03 \mathrm{M}$, and $0.01 \mathrm{M} \mathrm{NaOH}$.

\subsubsection{Methods}

To remove minor impurities from NGS solvent, thus simplifying the GC-FID chromatographs, the full solvent can be subjected to the standard NGS-CSSX washing protocol for the removal of minor impurities. Using a separatory funnel, the solvent is contacted sequentially with equal volumes of $0.01 \mathrm{M} \mathrm{HCl}, \mathrm{H}_{2} \mathrm{O}$, and decreasing concentrations of $\mathrm{NaOH}(0.30 \mathrm{M}, 0.10 \mathrm{M}, 0.03 \mathrm{M}$ and $0.01 \mathrm{M})$, and finally with $\mathrm{H}_{2} \mathrm{O}$ until the contact is $\mathrm{pH}$ neutral.

\subsection{GC PROTOCOL}

\subsubsection{Materials}

GC analyses were performed using a Hewlett Packard HP6850 Series GC System with Agilent Chem Station data and control software, Revision B.04.02 SP1. Two comparable columns were used and found to have similar retention times and responses. The first was an Agilent J\&W CP8907 GC column with a VF-1ms stationary phase. The column measured $15 \mathrm{~m}$ (L) × $0.25 \mathrm{~mm}$ (OD) x $0.39 \mathrm{~mm}$ (ID). The second was a General Separations Technologies, Inc., GS-Tek GsBP-1MS 100\% dimethylpolysiloxane column (part number 1125-1502) measuring $15 \mathrm{~m}$ (L) x $0.25 \mathrm{~mm}$ (ID) x $0.25 \mu \mathrm{m}$ film thickness. A Parker Balston H2PEM-100 Hydrogen Generator supplied hydrogen for the FID and carrier gas.

Since solvent samples are diluted 1:5 in DCM and analyzed via 2:1 split injection, a $4 \mathrm{~mm}$ ID Agilent (part \# 5183-4647) single taper glass liner with an $880 \mu \mathrm{L}$ vapor volume capacity and fitted with a bottom nub (for sample passage to the split vent) is used. The vapor volume should be sufficient to allow for the vapor expansion of DCM in the $250{ }^{\circ} \mathrm{C}$ inlet. The liner contains glass wool to assist in the volatilization of sample and to act as a trap for MaxCalix, a non-volatile solvent component.

The Agilent J\&W CP8907 GC column was selected since it exhibits low polarity and is highly inert. Manufacturer's specifications indicate that this column has a $100 \%$ dimethylpolysiloxane stationary phase that is highly dispersive and will afford the rapid elution of highly volatile hydrocarbons due to lack of hydrogen-bonding strength. It is characterized by low bleed (which allows for increased sensitivity) and the $0.25 \mathrm{~mm}$ ID makes for higher column efficiency, providing approximately 4,750 theoretical plates per meter. The combination of film thickness and column ID gives a column capacity of 50-100 ng of sample, which permits longer sample retention time on the column while the 15-meter column length is suitable for samples containing few solutes. The General Separations Technologies, Inc., GS-Tek GsBP-1MS was a nearly identical column to the J\&W CP8907 with the same physical characteristics and resulting separation capabilities. This low polarity, low-bleed column is highly dispersive and rapidly elutes hydrocarbon solvent, retaining other components longer thereby permitting good separation.

The $N, N^{\prime}, N^{\prime}$ '-tris(3,7-dimethyloctyl)guanidine (TiDG), lot no. 79-179-1, was obtained from Marshallton. The 3,7-dimethyloctan-1-amine (isodecylamine, iDA) was synthesized by P. V. Bonnesen, 
PB-CSG-2010-8-1, while di-isodecylurea was synthesized by Neil Williams and designated as lot number NJW-20Feb15.

Additional laboratory equipment included a VWR Digital Vortex Mixer (model 14005-824), VWR Clinical 50 centrifuge and VWR Ultrasonic Cleaner/Heating Bath (model 97043-988). Several thermometers, Eppendorf Research pipettes, an Ohaus AR2140 balance and a check weight set used in this work, were calibrated by ORNL Metrology (accredited to ISO/IEC 17025 by the National Voluntary Laboratory Accreditation Program).

\subsubsection{Methods}

The starting point for method development used conditions that were previously employed for analyzing the modifier breakdown product 4-sec-butylphenol ${ }^{14}$ from NGS solvent. The initial program tested was 4sBPG-M (see Table 2.3), which was the program developed for the analysis of 4-sec-butylphenol. An adjustment to that program (Table 2.3), designated NSG-Gua1.M (Table 2.4), achieved an excellent separation of TiDG and its two breakdown components.

To establish the locations of specific products in the chromatogram, the initial test sample mixture contained $1 \mathrm{mM}$ each of TiDG, di-iDU, and iDA in dichloromethane (DCM). Once located in the chromatograph, the same products (TiDG, di-iDU, and iDA) were added together in NGS solvent, which was then diluted 1:5 in DCM for analysis. To identify various solvent components, a series of "partial NGS solvent" solutions were formulated and analyzed on the GC. This included Isopar alone, and Isopar in DCM, Cs-7SB in DCM, and Cs-7SB in Isopar, MaxCalix in DCM, and MaxCalix in Isopar, and TiDG in DCM, and TiDG in Isopar, then the full NGS solvent diluted 1:5 in DCM.

When using the full NGS solvent, it was noted that the signal peak for the iDA was obscured in the FID signal due to a long tail attributed to the Isopar L. So as to avoid the Isopar L FID signal, the method development was undertaken using TiDG, di-iDU, and iDA in DCM only. A semi-systematic approach was then taken in which most parameters (initial temperature, hold time, temperature climb rate, and total time) were varied.

QA/QC for this work included the use of calibrated equipment. Liquid transfers are performed using calibrated pipettes, and either graduated or volumetric glassware. Component weights were obtained using a calibrated Ohaus balance (ORNL designator X249310) used in conjunction with a set of calibrated check weights (ORNL designator A001507). Typically, two check weights (usually $1 \mathrm{~g}$ and $10 \mathrm{~g}$ ) were weighed both before and after the weighing of chemical reagents as a check on the consistency of the balance.

Table 2.3. Adjustments to basic program

\begin{tabular}{lcccc} 
Method & $\begin{array}{c}\text { Rate } \\
{ }^{\circ} \mathrm{C} / \mathrm{min}\end{array}$ & $\begin{array}{c}\text { Temp. } \\
{ }^{\circ} \mathrm{C}\end{array}$ & $\begin{array}{c}\text { Hold time } \\
(\mathrm{min})\end{array}$ & $\begin{array}{c}\text { Total } \\
\text { time }(\mathrm{min})\end{array}$ \\
\hline 4-sBPG-M & & 80 & 3 & 3 \\
& 100 & 260 & 0 & 4.8 \\
& 4 & 300 & 10 & 24.8 \\
\hline NSG-Gua1.M & & 45 & 1 & 1 \\
& 10 & 300 & 20 & 46.5 \\
\hline
\end{tabular}




\section{Table 2.4. Program (NGS-Gua1.M) established for TiDG breakdown products analysis}

ALS -

Syringe $-10.0 \mu \mathrm{L}$

Inj. Vol - $5.0 \mu \mathrm{L}$

Pre inj.

Sample washes 2

Solv. A washes 3

Solv. B washes 3

Sample Pump

Post inj.

$3 \quad$ Solvent $A=$ Water

$3 \quad$ Solvent B $=$ Methanol

Inlet -

Heater $\quad 250{ }^{\circ} \mathrm{C}$

Pressure $\quad 7.7 \mathrm{psi}$

Total flow $\left(\mathrm{H}_{2}\right) \quad 12.6 \mathrm{~mL} / \mathrm{min}$

Mode: Split $\quad$ Split ratio 2:1

$5.2 \mathrm{~mL} / \mathrm{min}$

Signals -

Data Rate/ minimum peak width $=20 \mathrm{~Hz} / 0.1 \mathrm{~min}$

\section{Column -}

Mode: Constant Flow

Set Point:
Pressure: $7.7 \mathrm{psi}$
Actual P 9.7 psi

Flow: $\quad 2.6 \mathrm{~mL} / \mathrm{min}$

Average Velocity: $74 \mathrm{~cm} / \mathrm{sec}$

Post run: $3.477 \mathrm{~mL} / \mathrm{min}$

\section{Oven -}

Initial Oven: $45^{\circ} \mathrm{C}$

Equilibrium time: $0.50 \mathrm{~min}$

Max. temp.: $300{ }^{\circ} \mathrm{C}$

Post run: $\quad 50^{\circ} \mathrm{C}$

Post run time: $0.00 \mathrm{~min}$

\begin{tabular}{c} 
Rate \\
${ }^{\circ} \mathrm{C} / \mathrm{min}$ \\
\hline
\end{tabular}

Temp.

Hold Time

Total

NSG-Gua1.M

10

45

$\min$

Time (min)

\section{Detector -}

Heater: $305^{\circ} \mathrm{C}$

$\mathrm{H} 2$ Flow: $35.0 \mathrm{~mL} / \mathrm{min}$

Air Flow: $280 \mathrm{~mL} / \mathrm{min}$

Flame

Electrometer

Lit Offset $-2.0 \mathrm{pA}$

Column - $\quad$ GS-Tek GsBP-1MS $(15 \mathrm{~m} \times 0.250 \mathrm{~mm} \times 0.25 \mu \mathrm{m})$ 
An Agilent/HP 6850 Gas Chromatograph equipped with Agilent Chem Station for GC data and control software, an FID detector was used, along with either an Agilent J\&W CP8907 GC column or a GS-Tek GsBP-1MS $(15 \mathrm{~m} \times 0.250 \mathrm{~mm} \times 0.25 \mu \mathrm{m})$. A $5 \mu \mathrm{L}$ sample volume was introduced via 2:1 split injection into the injection port that was set at a temperature of $250{ }^{\circ} \mathrm{C}$. The carrier gas was $\mathrm{H}_{2}$ set in constant flow mode at $2.6 \mathrm{~mL} / \mathrm{min}$ (a nominal head pressure of $7.7 \mathrm{psi}$, to give an average linear velocity of $74 \mathrm{~cm} / \mathrm{s}$ ). The detector was set at $305{ }^{\circ} \mathrm{C}$ with an $\mathrm{H}_{2}$ flow of $35 \mathrm{~mL} / \mathrm{min}$, a compressed air flow of $280 \mathrm{~mL} / \mathrm{min}$, and no make-up gas. The data rate was $20 \mathrm{~Hz}$ with a minimum peak of $0.01 \mathrm{~min}$.

In order for the GC software to calculate the amounts of TiDG, di-iDU, and iDA in any given sample, standard curves were constructed using three dilution series (Tables 2.5, 2.6, and 2.7), one for each of these three compounds, ranging in concentration from $0.0 \mathrm{M}$ to $0.003 \mathrm{M}$. The Agilent Chem Station GC software maintains a Calibration Table and plots a Calibration Curve (Figure 2.1 A \& B from Agilent J\&W CP8907 GC column). The integrated values from under the individual CG-FID traces can also be manually plotted as in Figure 2.2 A\&B (using GS-Tek GsBP-1MS column).

Table 2.5 Serial dilutions of stock 3 mM TiDG for standard curve

\begin{tabular}{rccc}
$\begin{array}{c}\text { [TiDG] } \\
\text { in mM }\end{array}$ & $\begin{array}{c}\text { Amount of } 3 \mathrm{mM} \\
\text { TiDG added }(\mu \mathrm{L})\end{array}$ & $\begin{array}{c}\text { Amount of DCM } \\
\text { added }(\mu \mathrm{L})\end{array}$ & ng TiDG $/ \mu \mathrm{L}$ \\
\hline 3.0 & 1500 & 0 & 1549.17 \\
2.5 & 1250 & 250 & 1290.97 \\
2.0 & 1000 & 500 & 1032.78 \\
1.5 & 750 & 750 & 774.59 \\
1.0 & 500 & 1000 & 516.39 \\
0.5 & 250 & 1250 & 258.19 \\
0.0 & 0 & 1500 & 00.00 \\
\hline
\end{tabular}

* The parent solution for the starting amine (TiDG) dilution series was $10.0 \mathrm{~mL}$ of 3.0 $\mathrm{mM}$ TiDG in DCM. $15.49 \mathrm{mg}$ was weighed into a $10 \mathrm{~mL}$ volumetric, and DCM was added to the mark.

Table 2.6 Serial dilutions of stock $3 \mathrm{mM}$ di-isodecylurea for standard curve

\begin{tabular}{rccc}
$\begin{array}{c}\text { di-iDU] } \\
\text { in } \mathrm{mM}\end{array}$ & $\begin{array}{c}\text { Amount of } 3 \mathrm{mM} \\
\text { di-iDU added }(\mu \mathrm{L})\end{array}$ & $\begin{array}{c}\text { Amount of DCM } \\
\text { added }(\mu \mathrm{L})\end{array}$ & ng di-iDU $/ \mu \mathrm{L}$ \\
\hline 3.0 & 1500 & 0 & 1021.77 \\
2.5 & 1250 & 250 & 851.47 \\
2.0 & 1000 & 500 & 681.18 \\
1.5 & 750 & 750 & 510.88 \\
1.0 & 500 & 1000 & 340.59 \\
0.5 & 250 & 1250 & 170.30 \\
0.0 & 0 & 1500 & 00.00 \\
\hline
\end{tabular}

* The parent solution for the urea degradation product (di-iDU) dilution series was $10.0 \mathrm{~mL}$ of $3.0 \mathrm{mM}$ di-iDU in DCM. $10.22 \mathrm{mg}$ was weighed into a $10 \mathrm{~mL}$ volumetric, and DCM was added to the mark. 
Table 2.7 Serial dilutions of stock $3 \mathrm{mM}$ 3,7-dimethyloctan-1-amine for standard curve

\begin{tabular}{|c|c|c|c|}
\hline $\begin{array}{l}{[\mathrm{iDA}]} \\
\text { in } \mathrm{mM}\end{array}$ & $\begin{array}{l}\text { Amount of } 3 \mathrm{mM} \\
\text { iDA added }(\mu \mathrm{L})\end{array}$ & $\begin{array}{l}\text { Amount of DCM } \\
\text { added }(\mu \mathrm{L})\end{array}$ & ng iDA / $\mu \mathrm{L}$ \\
\hline 3.0 & 1500 & 0 & 471.9 \\
\hline 2.5 & 1250 & 250 & 393.25 \\
\hline 2.0 & 1000 & 500 & 314.6 \\
\hline 1.5 & 750 & 750 & 235.95 \\
\hline 1.0 & 500 & 1000 & 157.3 \\
\hline 0.5 & 250 & 1250 & 78.65 \\
\hline 0.0 & 0 & 1500 & 00.00 \\
\hline
\end{tabular}

* The parent solution for the amine degradation product (iDA) dilution series was $10.0 \mathrm{~mL}$ of $3.0 \mathrm{mM}$ iDA in DCM. $4.72 \mathrm{mg}$ was weighed into a $10 \mathrm{~mL}$ volumetric, and DCM was added to the mark.

A. Standard Curve for TiDG with column 1 (Agilent J\&W CP8907 GC)

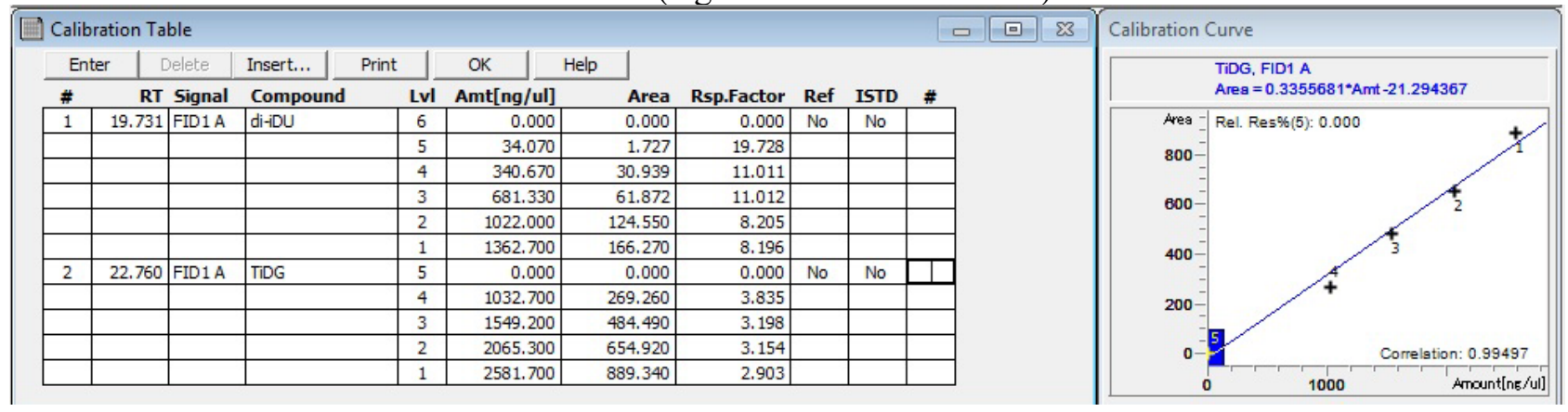

B. Standard Curve for di-iDU with column 1 (Agilent J\&W CP8907 GC)

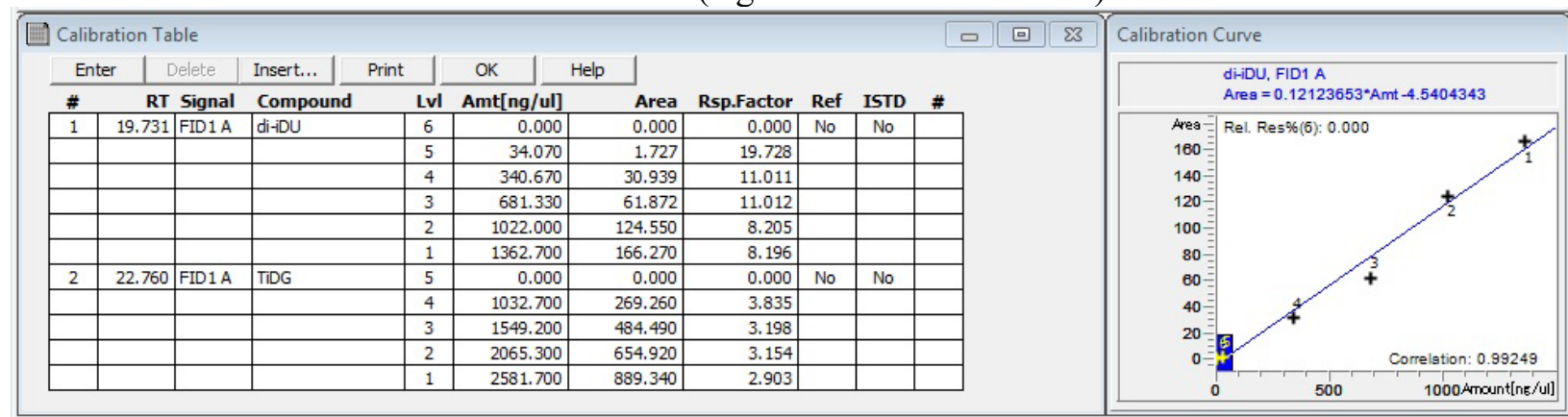

* These tables and calibration curves were generated by Agilent Chem Station 6850 for GC software from data yielded from individual calibration samples, diluted 1:10 in DCM, of 0-3 mM of TiDG and di-iDU. The curve for iDA is not shown as this degradation product is expected to wash out of the solvent.

Figure 2.1 Calibration Tables \& Curves for di-iDU and TiDG - column 1 (Agilent J\&W CP8907 GC) 
A. Standard Curve for TiDG with column 2 (GS-Tek GsBP-1MS)

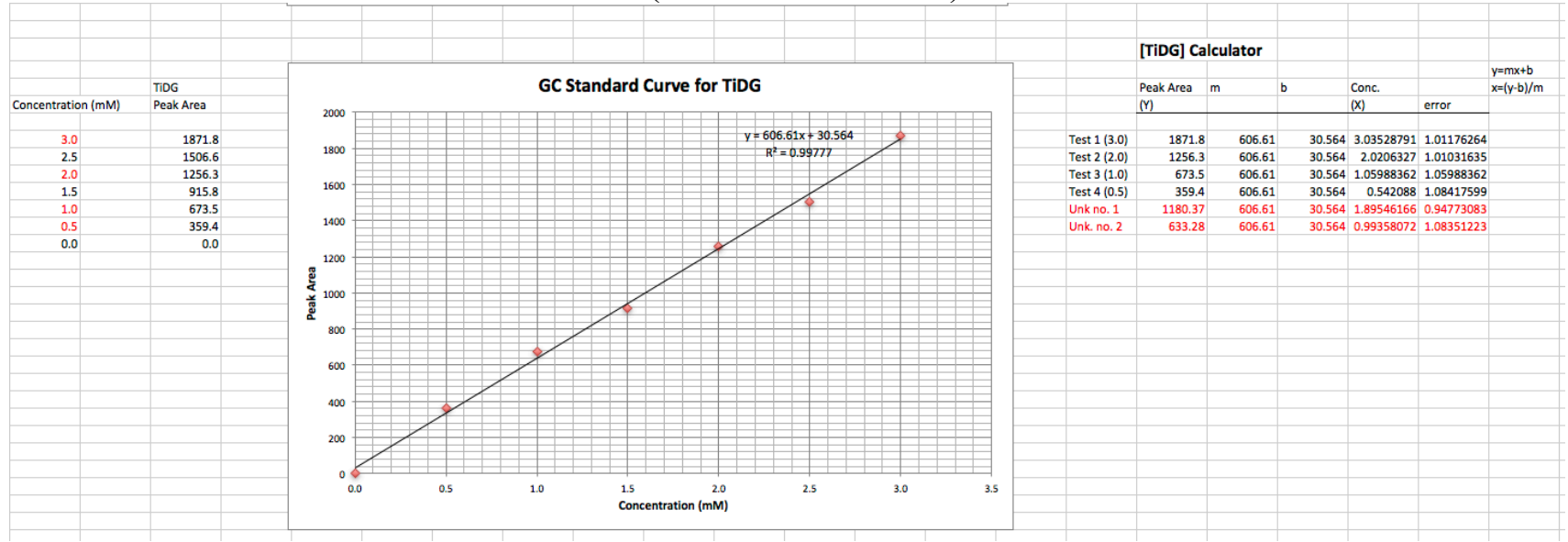

B. Standard Curve for di-iDU with column 2 (GS-Tek GsBP-1MS)
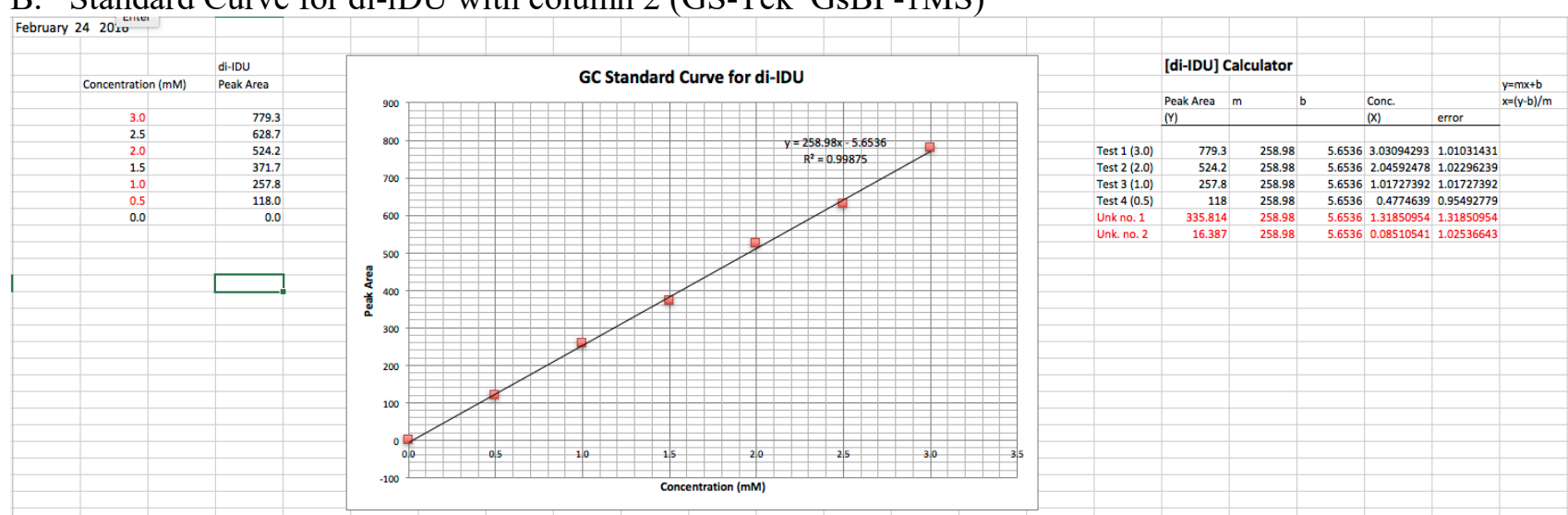

* These tables and calibration curves were generated by plotting, via Excel, data yielded from individual calibration samples of 0-3 mM of TiDG and di-iDU that had been diluted 1:5 in DCM prior to injection. The curve for iDA is not shown as this degradation product is expected to wash out of the solvent. The column used was a GS-Tek GsBP$1 \mathrm{MS}$.

Figure 2.2 Calibration Tables \& Curves for di-iDU and TiDG - column 2 (GS-Tek GsBP-1MS)

\subsection{TIDG DEGRADATION TESTING OF AGED NGS SOLVENT}

Samples of full NGS solvent were stored for a period of 19 months at either $25^{\circ} \mathrm{C}$ or $35^{\circ} \mathrm{C}$. Half of the samples were subjected to the washing protocol (see section 2.2.2 Methods in this report) normally used prior to benchtop extraction tests. This washing procedure places the guanidinium in its neutral form, which is the typical form found in the solvent during active use ${ }^{12}$ at the MCU or SWPF. The other half of the samples were not so washed, remaining in the protonated form. Following their 1:10 dilution in DCM, these solvents were analyzed by the GC-FID method outlined in this report using the Agilent J\&W CP8907 
GC column to discern what breakdown products, if any, are present and the degree to which the solvent samples have degraded.

Since the tail of the Isopar-L peak hides the iDA, the concentration of that degradation product was determined by ESI-MS. ${ }^{15}$ Stock solutions of IDA and N-15-iDA (Marshallton) were prepared by weight to a concentration of approximately $3 \mathrm{mM}$ (exact $\mu \mathrm{g} / \mathrm{g}$ concentrations were $468 \mu \mathrm{g} / \mathrm{g}$ and $383 \mu \mathrm{g} / \mathrm{g}$, slightly lower than $3 \mathrm{mM}$ due to dilution error-but as this concentration is used this will not affect the results). ${ }^{15}$ The method was validated by preparing a 1:1 sample by weight and the spreadsheets previously developed were altered to calculate the weight (and thus the concentration) of the iDA in the sample based on the concentration of the N-15-iDA spike, the weights of both spiked solutions, and the measured isotopics. After spiking with N-15-iDA the concentration of iDA in the stored solutions was determined and the results summarized. ${ }^{15}$ 


\section{RESULTS AND DISCUSSION}

\subsection{GC METHOD}

Through the use of synthesized, authentic TiDG and di-iDU, the locations of this guanidine and its urea degradation product were fixed in the GC-FID chromatogram (Fig. 3.1, Tables 3.2-3.3). Individual NGS components (Isopar, Cs-7SB, and MaxCalix), were injected both individually and collectively, and their locations were similarly identified and fixed to specific locations in the chromatogram (Figs 3.2-3.6). Standard curves were developed for both the nearly identical Agilent J\&W CP8907 GC and GS-Tek GsBP1 MS columns, the GS-Tek column was used for both the method validation (Table 3.3) and the analysis of the solvent that had been stored for 19 months (Table 3.4).

Due to the large and prominent 'tail' from Isopar's FID signal, the iDA signal is masked. If it's necessary to quantify the amount of iDA present in the solvent, it will have to be extracted from the NGS solvent using DCM. The solvent would be contacted with an equal volume of DCM, vortexed once or twice for $30 \mathrm{~s}$ each time, then centrifuged at $3500 \mathrm{rpm}$ for 6-8 min. The DCM layer is recovered for analysis by GC-FID. The method, established for an Agilent/HP 6850 Gas Chromatograph equipped with Agilent Chem Station data and control software, a FID detector and a GS-Tek GsBP-1 MS $(15 \mathrm{M} \times 0.250 \mathrm{~mm} \times$ $0.25 \mu \mathrm{m}) \mathrm{GC}$ column, is described in detail in Table 2.4. Subjecting the DCM extracted samples to these analytical conditions should result in a clean, symmetrical peak at $\sim 6$ min (Fig. 3.1).

In the case of the analysis of the long-term storage solvent, ESI-MS had been used in separate work, ${ }^{15}$ and the iDA results from that work were included in Table 3.4, 'GC determination of degradation of TiDG in stored NGS solvent'.

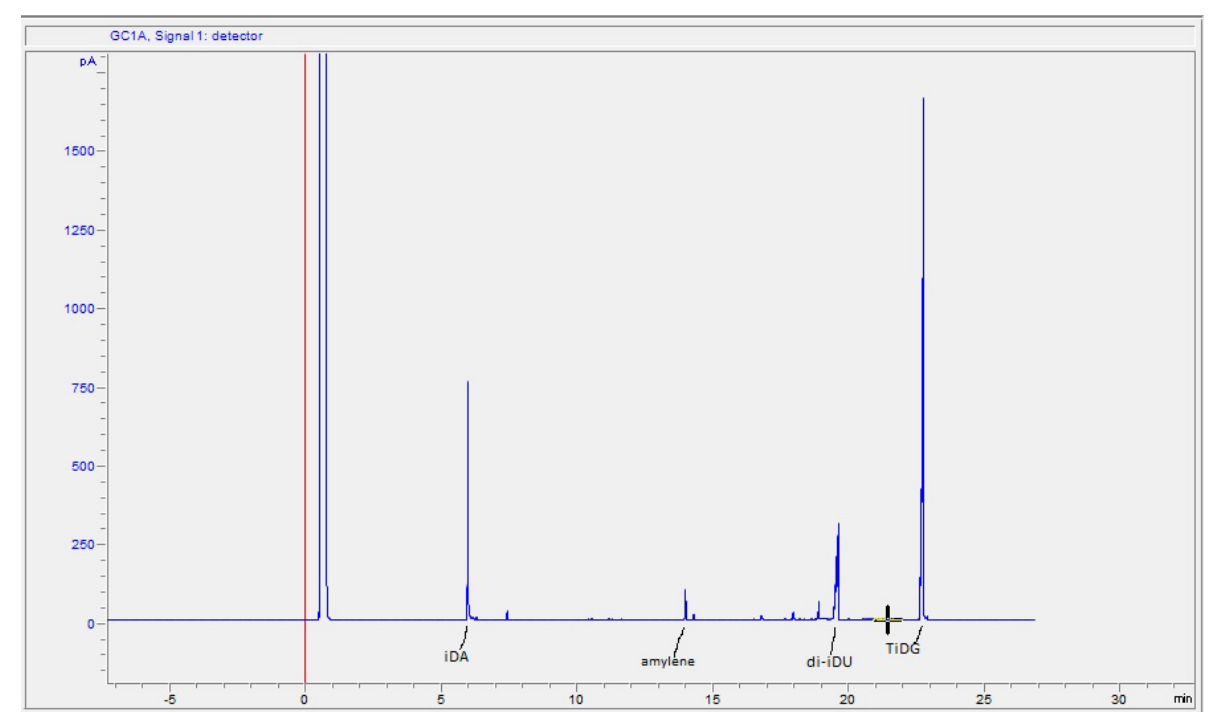

* amylene is the stabilizer found in DCM, the diluent used for GC analysis of NGS solvent

Fig. 3.1 Chromatogram obtained using GC method NGS-Gua1.M showing well-separated peaks of TiDG, di-iDU, and iDA in the absence of Isopar-L, MaxCalix and Cs-7SB. 


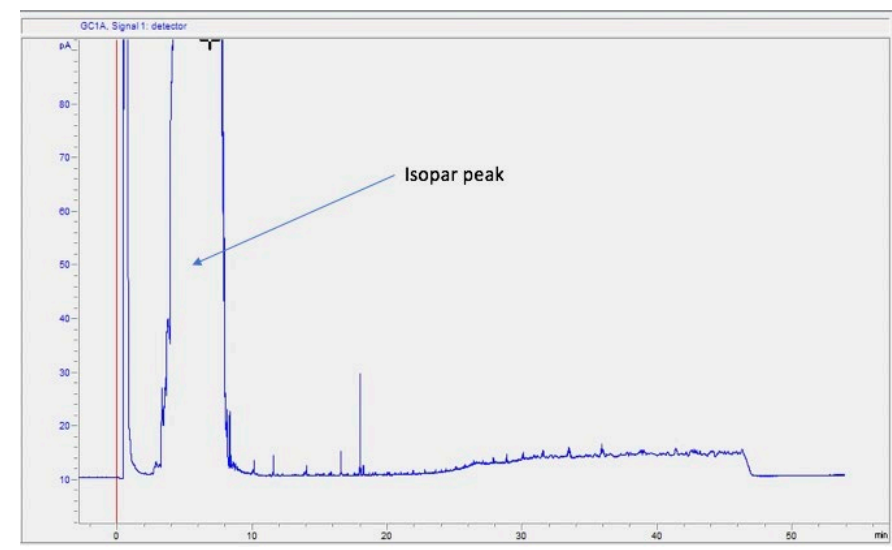

Fig. 3.2 Chromatogram showing 1:10 dilution of Isopar in DCM.

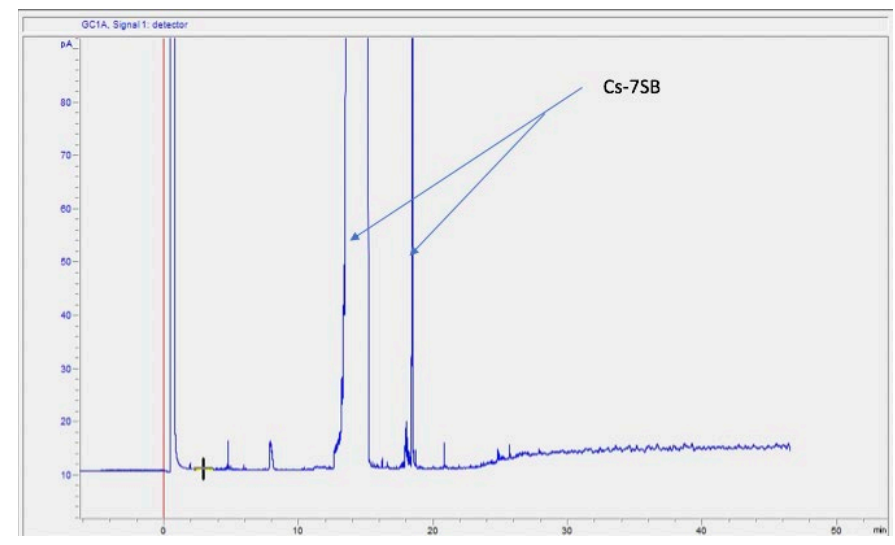

Fig. 3.3 Chromatogram of 1:10 dilution of 0.5 M Cs-7SB in DCM.

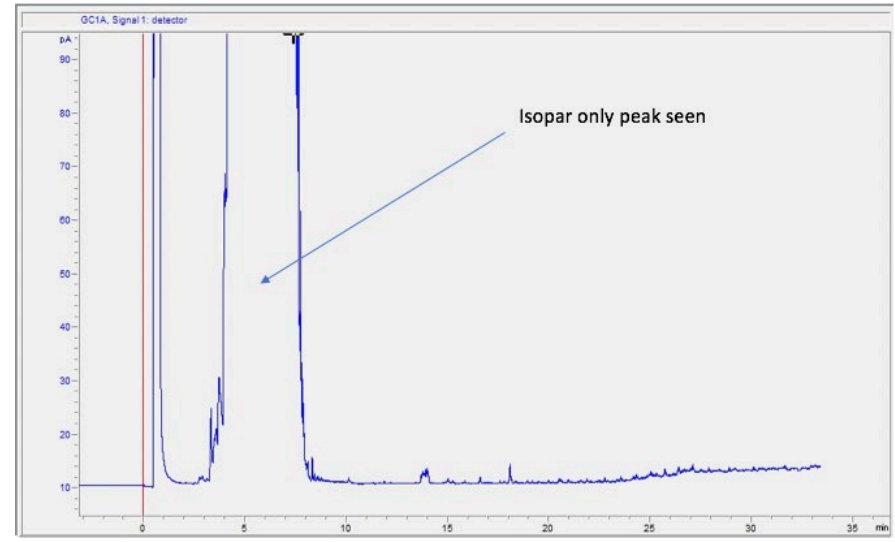

Fig. 3.4. Chromatogram of 1:20 dilution of $50 \mathrm{mM}$ MaxCalix in Isopar diluted in DCM. * MaxCalix is not seen in this chromatogram since it's low volatility results in it hanging up on the glass wool in the top of the injector liner. 


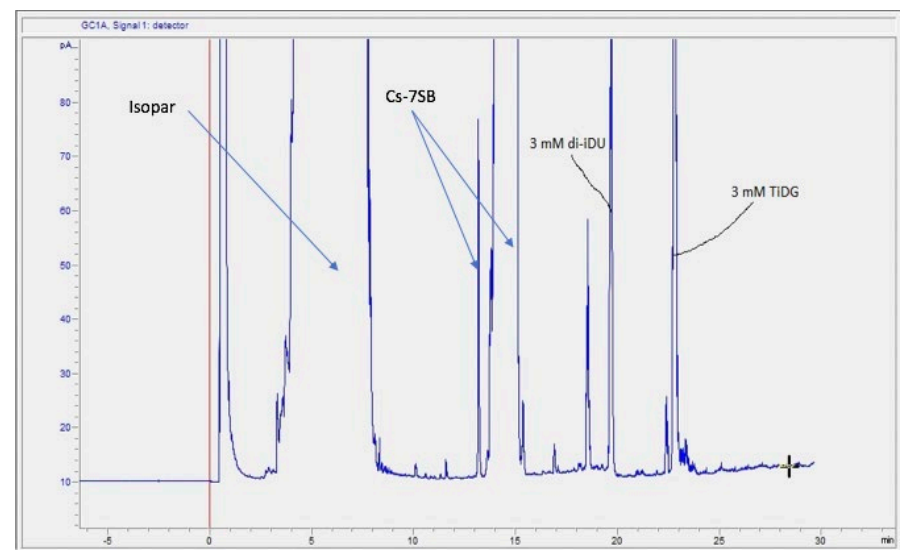

Fig. 3.5 Chromatogram of 1:10 dilution (in DCM) of Full NGS Solvent also containing 3 mM di-Isodecylurea.

Sample Chromatogram

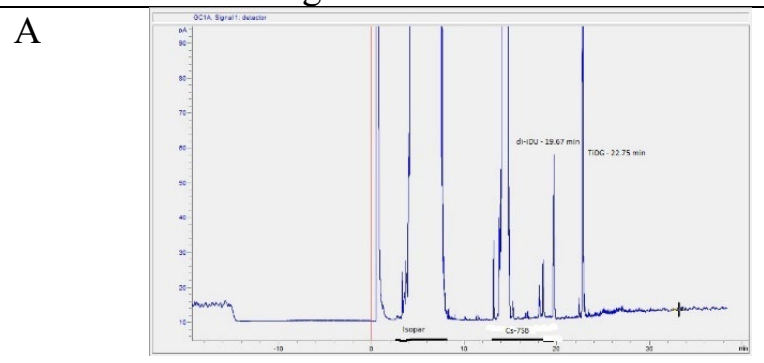

Modified NGS Solvent (0.5 M Cs-7SB, 3mM TiDG $+3 \mathrm{mM}$ di-iDU, in Isopar) diluted 1:20 in DCM.

$\mathrm{C}$

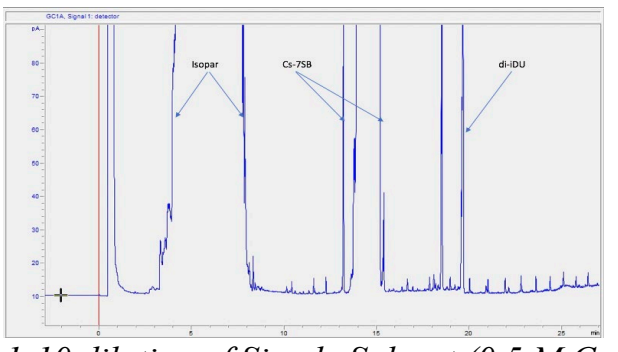

1:10 dilution of Simple Solvent $(0.5 \mathrm{MCS}$ $7 S B$, 3 mM di-iDU, Isopar, no MaxCalix) in $D C M$

E

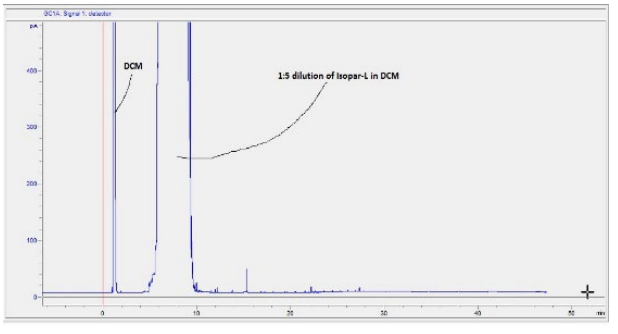

1:5 dilution of Isopar- $L$ in DCM
Sample Chromatogram

B

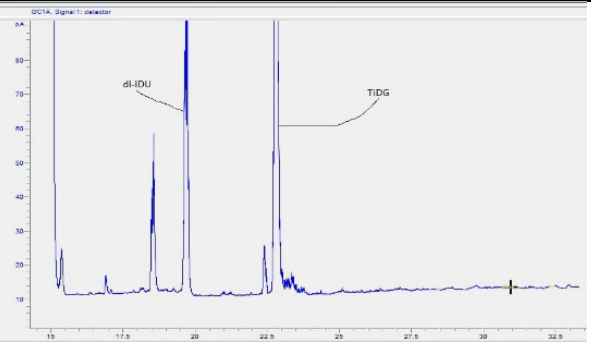

Subsection of Chromatogram of Full NGS Solvent (diluted 1:10 in DCM) with $3 \mathrm{mM}$ di-iDU added showing di-iDU and TiDG locations.

D

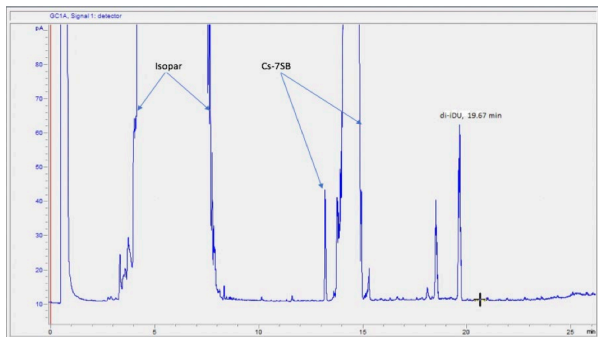

1:20 dilution of Simple Solvent ( 0.5 M Cs7SB, $3 \mathrm{mM}$ di-iDU, Isopar, no MaxCalix) in DCM.

F

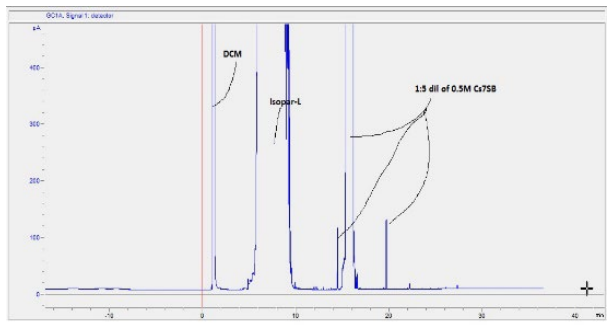

1:5 dilution of Isopar- $L$ \& Cs-7SB in DCM

Fig. 3.6 GC Chromatograms of Various Solvent Components-Individually \& in Combination 


\title{
3.1.1 Sample injection process and considerations
}

A one microliter sample of NGS solvent is diluted 1:5 in DCM and analyzed via 2:1 split injection. The strength of the FID signal is such that solvent can alternatively be diluted 1:10 or 1:20 with sufficient signal to quantify the guanidine and the urea degradation products. If those alternative dilution protocols are to be used, correction factors must be employed to account for the dilution either post-run, or a dilution adjustment should be made to the TiDG and di-iDU standards prior to the construction of their respective standard curves. The program to be followed was designated NGS-Gua1.M, and it is shown below as Table 3.1, and the calibration curves previously constructed are shown as figures 3.7 and 3.8. The GC's inlet temperature is set at $250{ }^{\circ} \mathrm{C}$, and a $4 \mathrm{~mm}$ ID Agilent (part \# 5183-4647, which is the leading split liner recommended by Agilent) single taper glass liner with an $880 \mu \mathrm{L}$ vapor volume capacity is used. The liner contains glass wool to assist in volatilization of sample and to act as a trap for the non-volatile MaxCalix solvent component. The liner is fitted with a bottom nub to allow for the passage of the sample to the split vent.

The injector liner will soon become dirty due to the retention of the non-volatile MaxCalix, so it is recommended that the liner, along with the septum and gold seal be frequently changed-out. If NGS solvent is to be routinely analyzed by the operators of the MCU/SWFP, these disposable items should be changedout prior to any new series of analyses. Depending on the number of solvent analyses routinely performed, monthly replacement of the liner, septum, and gold seal might be appropriate.

\section{Table 3.1. Program (NGS-Gua1.M) established for TiDG breakdown products analysis}

\author{
ALS - \\ Syringe $-10.0 \mu \mathrm{L}$ \\ Inj. Vol - $5.0 \mu \mathrm{L}$ \\ Pre inj. $\quad$ Post inj. \\ Sample washes 2 \\ Sample Pump \\ Inlet - \\ Heater $\quad 250{ }^{\circ} \mathrm{C}$ \\ Pressure $\quad 7.7 \mathrm{psi}$ \\ Total flow $\left(\mathrm{H}_{2}\right) \quad 12.6 \mathrm{~mL} / \mathrm{min}$ \\ Mode: Split $\quad$ Split ratio 2:1 $5.2 \mathrm{~mL} / \mathrm{min}$ \\ Signals - \\ Data Rate/ minimum peak width $=20 \mathrm{~Hz} / 0.1 \mathrm{~min}$ \\ Column - \\ Mode: Constant Flow \\ Set Point: \\ Pressure: $7.7 \mathrm{psi} \quad$ Actual P $9.7 \mathrm{psi}$ \\ Flow: $\quad 2.6 \mathrm{~mL} / \mathrm{min}$ \\ Average Velocity: $74 \mathrm{~cm} / \mathrm{sec}$ \\ Post run: $3.477 \mathrm{~mL} / \mathrm{min}$ \\ Oven - \\ Initial Oven: $45^{\circ} \mathrm{C}$ \\ Equilibrium time: $0.50 \mathrm{~min}$ \\ Max. temp.: $300{ }^{\circ} \mathrm{C}$
}

$\begin{array}{llll}\text { Solv. A washes } & 3 & 3 & \text { Solvent A }=\text { Water }\end{array}$

$\begin{array}{llll}\text { Solv. B washes } & 3 & 3 & \text { Solvent B }=\text { Methanol }\end{array}$ 
Post run: $\quad 50{ }^{\circ} \mathrm{C}$

Post run time: $0.00 \mathrm{~min}$

\begin{tabular}{cccc}
$\begin{array}{c}\text { Rate } \\
{ }^{\circ} \mathrm{C} / \mathrm{min}\end{array}$ & $\begin{array}{c}\text { Temp. } \\
{ }^{\circ} \mathrm{C}\end{array}$ & $\begin{array}{c}\text { Hold Time } \\
\min \end{array}$ & $\begin{array}{c}\text { Total } \\
\text { Time (min) }\end{array}$ \\
\hline & & & \\
10 & 45 & 1 & 1 \\
& 300 & 20 & 46.5 \\
\hline
\end{tabular}

\section{Detector -}

Heater: $305^{\circ} \mathrm{C}$

H2 Flow: $35.0 \mathrm{~mL} / \mathrm{min}$

Air Flow: $280 \mathrm{~mL} / \mathrm{min}$

Flame

Electrometer

Lit Offset $-2.0 \mathrm{pA}$

\section{Column - $\quad$ GS-Tek GsBP-1MS $(15 \mathrm{~m} \times 0.250 \mathrm{~mm} \times 0.25 \mu \mathrm{m})$}

* This table is a reposting of Table 2.4. It is placed here for the convenience of the technologist wishing to use this method for TiDG \& di-iDU analysis.

When using this program, the TiDG and di-iDU components can be quantified in less than 25 minutes. The 'bake-out' at $300{ }^{\circ} \mathrm{C}$ for 20 minutes, followed by the cool-down phase ( $\sim 15$ minutes) for the oven and column, results in the ability to analyze a new solvent sample every 60 to 70 minutes.

In order for the GC software to calculate the amount of TiDG and di-iDU in any given sample, standard curves were constructed for both TiDG and di-iDU using the method NGS-Gua1.M and a dilution series for each component (Tables 2.5 and 2.6). The resulting standard curves, figures 3.7 and 3.8, with linear correlation coefficients of 0.9978 and 0.9988 respectively, were used to successfully validate the method by quantifying test mixtures (Table 3.2) with high accuracy (Table 3.3).

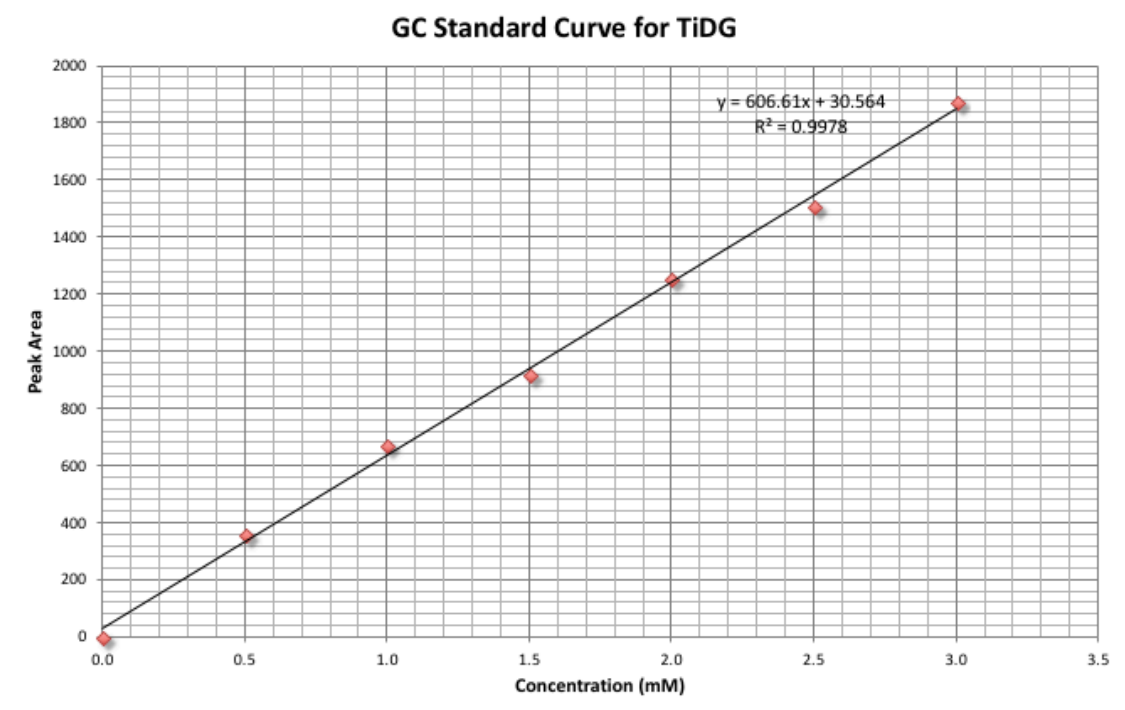

Fig. 3.7 Calibration curve of TiDG in DCM obtained using method NGS-Gua1.M-Column 2. 


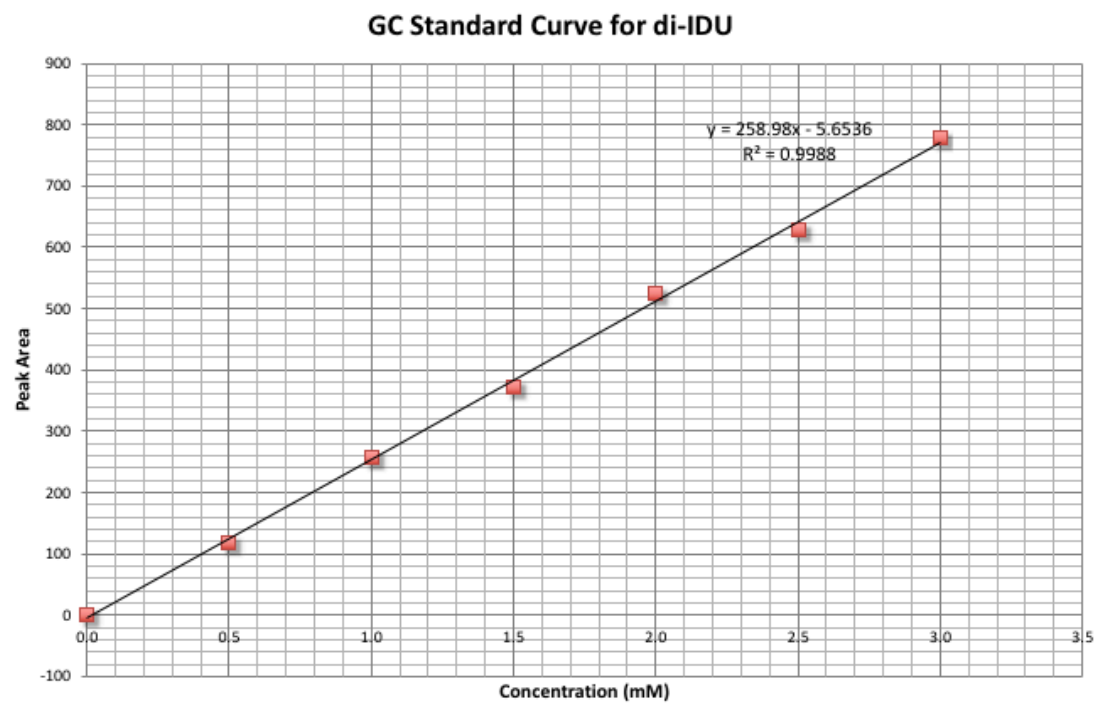

Fig. 3.8 Calibration curve of di-iDU in DCM obtained using method NGS-Gua1.M-Column 2.

\subsection{TESTING ABILITY OF THE GK COLUMN AND THE NSG-GUA 1.M METHOD TO CORRECTLY MEASURE GUANIDINES}

Following the establishment of standard curves, a series of NGS solutions, diluted 1:5 in DCM, lacking MaxCalix, but including 0.5M Cs-7SB in Isopar L and both TiDG and di-iDU were made (Table 3.2) and tested using the Table 3.1 method. The results (Table 3.3) showed close agreements between the as-made TiDG and di-iDU concentrations and the instrument-derived quantifications. The chromatograms generated during these analyses are found in figure 3.9.

Table 3.2. Dilution Series for GC Standard Curve for 1:5 dil. of 3.0 mM TiDG, $3.0 \mathrm{mM}$ di-IDU, 3.0 mM iDA, 0.5M Cs7SB / Isopar Solvent

(effectively this produces a 1:5 diluted sample, ready for GC analysis)

\begin{tabular}{|c|c|c|c|c|c|c|c|c|c|}
\hline $\begin{array}{l}\text { Sample } \\
\text { No. }\end{array}$ & $\begin{array}{c}\text { Concentration } \\
\text { (1:5 dil conc) }\end{array}$ & $\begin{array}{c}20 \mathrm{mM} \\
\text { TiDG } \\
\text { in DCM }\end{array}$ & $\begin{array}{c}20 \mathrm{mM} \\
\text { di-IDU } \\
\text { in } \mathrm{DCM}\end{array}$ & $\begin{array}{c}20 \mathrm{mM} \\
\text { iDA in } \\
\text { DCM }\end{array}$ & $\begin{array}{c}\text { 1.0mM } \\
\text { Cs7SB/Isopar }\end{array}$ & Isopar & DCM & $\begin{array}{c}3.0 \mathrm{mM} \\
\text { Parent }\end{array}$ & $\begin{array}{c}\text { Total } \\
\text { Volume }\end{array}$ \\
\hline 6 & $3.0 \mathrm{mM}(0.6)$ & $225 \mu \mathrm{L}$ & $225 \mu \mathrm{L}$ & $225 \mathrm{uL}$ & $750 \mu \mathrm{L}$ & $750 \mu \mathrm{L}$ & $5325 \mu \mathrm{L}$ & ---------- & $7500 \mu \mathrm{L}$ \\
\hline 5 & $2.5 \mathrm{mM}(0.5)$ & -------- & ---------- & --------- & $25 \mu \mathrm{L}$ & $25 \mu \mathrm{L}$ & $200 \mu \mathrm{L}$ & $1250 \mu \mathrm{L}$ & $1500 \mu \mathrm{L}$ \\
\hline 4 & $2.0 \mathrm{mM}(0.4)$ & -------- & ---------- & --------- & $50 \mu \mathrm{L}$ & $50 \mu \mathrm{L}$ & $400 \mu \mathrm{L}$ & $1000 \mu \mathrm{L}$ & $1500 \mu \mathrm{L}$ \\
\hline 3 & $1.5 \mathrm{mM}(0.3)$ & ------- & ---------- & -------- & $75 \mu \mathrm{L}$ & $75 \mu \mathrm{L}$ & $600 \mu \mathrm{L}$ & $750 \mu \mathrm{L}$ & $1500 \mu \mathrm{L}$ \\
\hline 2 & $1.0 \mathrm{mM}(0.2)$ & -------- & ---------- & --------- & $100 \mu \mathrm{L}$ & $100 \mu \mathrm{L}$ & $800 \mu \mathrm{L}$ & $500 \mu \mathrm{L}$ & $1500 \mu \mathrm{L}$ \\
\hline 1 & $0.5 \mathrm{mM}(0.1)$ & ------- & ---------- & -------- & $125 \mu \mathrm{L}$ & $125 \mu \mathrm{L}$ & $1000 \mu \mathrm{L}$ & $250 \mu \mathrm{L}$ & $1500 \mu \mathrm{L}$ \\
\hline 0 & $0.0 \mathrm{mM}(0.0)$ & -------- & ---------- & --------- & $150 \mu \mathrm{L}$ & $150 \mu \mathrm{L}$ & $1200 \mu \mathrm{L}$ & ---------- & $1500 \mu \mathrm{L}$ \\
\hline
\end{tabular}




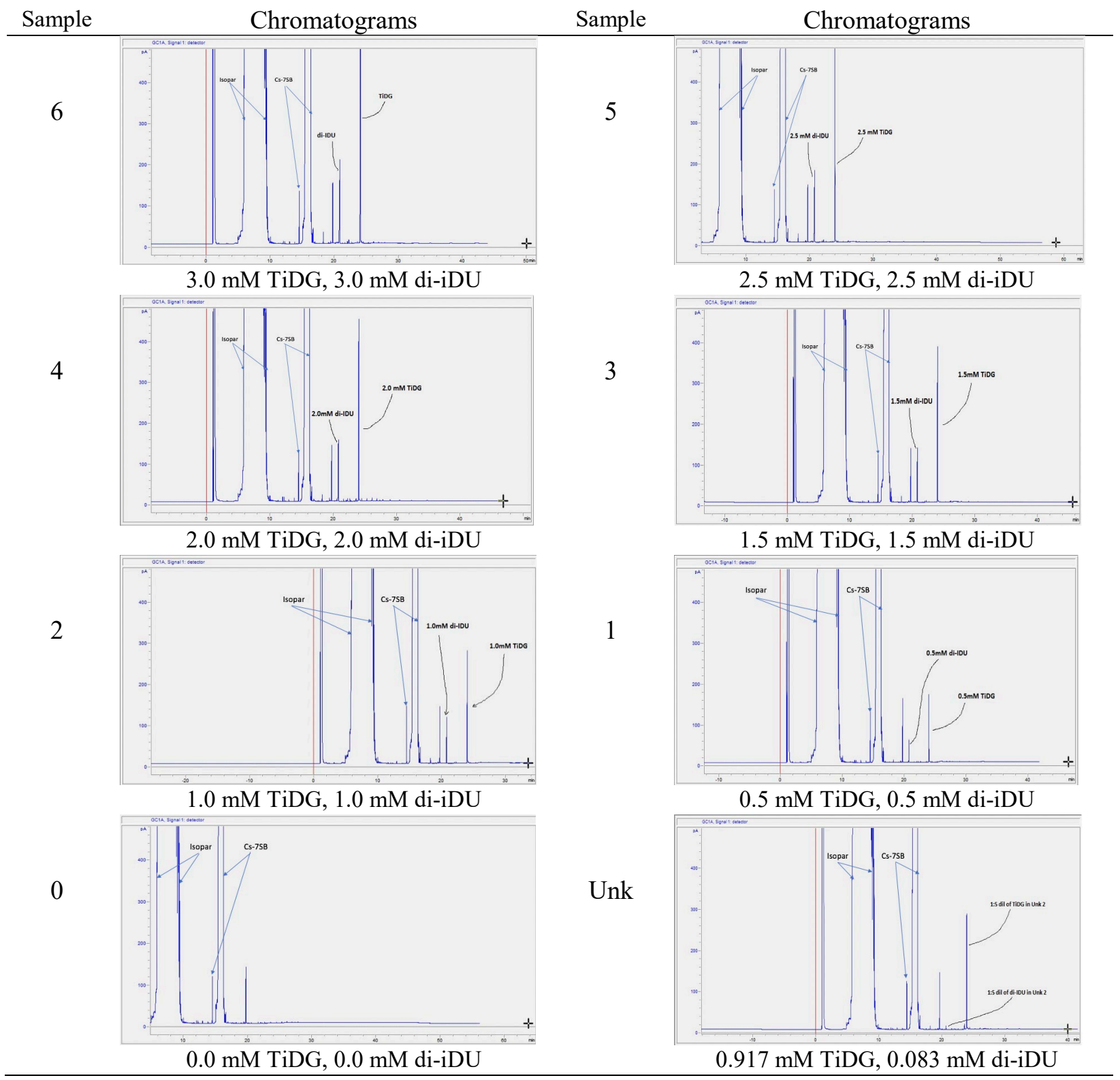

Fig. 3.9. Various GC Chromatograms of TiDG and di-iDU Mixtures in $0.5 \mathrm{M}$ Cs7SB/IsoparDiluted 1:5 in DCM. 
Table 3.3. Peak Area Data for Testing GC Standard Curves to Correctly Calculate Various Concentrations of TiDG and di-IDU in 0.5M Cs7SB / Isopar Diluted 1:5 in DCM

\begin{tabular}{|c|c|c|c|c|c|}
\hline $\begin{array}{l}\text { Sample } \\
\text { No. }\end{array}$ & $\begin{array}{l}\text { Concentration } \\
\text { of TiDG and di-IDU } \\
\text { (when diluted) }\end{array}$ & $\begin{array}{c}\text { (Time Range) } \\
\text { Peak Area for } \\
\text { di-IDU }\end{array}$ & $\begin{array}{l}\text { di-IDU Conc. as } \\
\text { determined by } \\
\text { GC }(\mathrm{mM})\end{array}$ & $\begin{array}{c}\text { (Time Range) } \\
\text { Peak Area for TiDG }\end{array}$ & $\begin{array}{l}\text { TiDG Conc. as } \\
\text { determined by } \\
\text { GC (mM) }\end{array}$ \\
\hline 6 & $3.0 \mathrm{mM}(0.6)$ & $\begin{array}{c}(20.790-20.834) \\
\mathbf{7 7 9 . 3 4} \\
(20.690-20.835)\end{array}$ & 3.031 & $\begin{array}{c}(23.895-24.208) \\
\mathbf{1 8 7 1 . 8 2} \\
(23.904-24.220)\end{array}$ & 3.035 \\
\hline 5 & $2.5 \mathrm{mM}(0.5)$ & $\begin{array}{c}\mathbf{6 2 8 . 6 6} \\
(20.687-20.829)\end{array}$ & 2.449 & $\begin{array}{c}\mathbf{1 5 0 6 . 5 9} \\
(23.899-24.272)\end{array}$ & 2.433 \\
\hline 4 & $2.0 \mathrm{mM}(0.4)$ & $\begin{array}{c}\mathbf{5 2 4 . 1 7} \\
(20.692-20.817)\end{array}$ & 2.045 & $\begin{array}{c}\mathbf{1 2 5 6 . 2 5} \\
(23.899-24.276)\end{array}$ & 2.020 \\
\hline 3 & $1.5 \mathrm{mM}(0.3)$ & $\begin{array}{c}\mathbf{3 7 1 . 6 5} \\
(20.704-20.810)\end{array}$ & 1.457 & $\begin{array}{c}\mathbf{9 1 5 . 8 0} \\
(23.907-24.224)\end{array}$ & 1.459 \\
\hline 2 & $1.0 \mathrm{mM}(0.2)$ & $\begin{array}{c}\mathbf{2 5 7 . 8 0} \\
(20.709-20.786)\end{array}$ & 1.017 & $\begin{array}{c}\mathbf{6 7 3 . 4 6} \\
(23.901-24.216)\end{array}$ & 1.059 \\
\hline 1 & $0.5 \mathrm{mM}(0.1)$ & $\begin{array}{c}118.01 \\
(20.70-20.78)\end{array}$ & 0.478 & $\begin{array}{c}\text { 359.42 } \\
23.9-24.2\end{array}$ & 0.542 \\
\hline 0 & $0.0 \mathrm{mM}(0.0)$ & $\begin{array}{c}\mathbf{0 . 3 2} \\
(20.790-20.84)\end{array}$ & 0.0230 & $\begin{array}{c}\mathbf{0 . 0} \\
(23.878-24.184)\end{array}$ & 0.050 \\
\hline Unk & $\begin{array}{l}0.083 \mathrm{mM} \text { di-IDU } \\
0.917 \mathrm{mM} \text { TiDG }\end{array}$ & 16.387 & 0.085 & 633.28 & 0.993 \\
\hline
\end{tabular}

\subsection{ANALYSIS OF AGED SOLVENT}

After this GC-FID method was validated by successfully determining the concentrations of TiDG and di-iDU in a number of test samples, it was then used to quantify the suppressor and its urea degradation byproduct in a number of NGS solvent samples that had been stored under various conditions for a 19month period. The samples were obtained from B. D. Roach's extensive study of various physical and chemical parameters involving the NGS solvent. ${ }^{15}$ Solvent samples obtained included both washed (guanidinium in the neutral form) and unwashed (guanidinium protonated), stored at $25{ }^{\circ} \mathrm{C}$ and $35{ }^{\circ} \mathrm{C}$ for the 19-month period.

Solvent samples (Table 3.4) were diluted 1:5 in fresh DCM and analyzed for TiDG and di-iDU following the method shown in Table 3.1. In addition, electrospray mass-spectrometry (ESI-MS) data was supplied by B. D. Roach quantifying the iDA degradation product. ${ }^{15}$ The GC-FID results indicated very little, if any, degradation of the unwashed (protonated) TiDG when stored at either $25{ }^{\circ} \mathrm{C}$ or $35{ }^{\circ} \mathrm{C}$. The calculated concentrations were shown to be higher $(3.73 \mathrm{mM}$ and $4.13 \mathrm{mM})$ than the amount added $(3.0 \mathrm{mM})$ to the NGS solvent 19 months before. This likely indicates that some amount of evaporation occurred over the test period, with slightly more evaporation seen at the higher storage temperature. No di-iDU was seen by GC-FID in the unwashed samples, further confirming no degradation of the protonated TiDG. ESI-MS data $^{15}$ showed no iDA in the samples, again confirming no TiDG degradation occurred over the 19-month storage period with the protonated form of the suppressor. The analyses of the neutral form of the TiDG showed degradation of the suppressor at both storage temperatures, although there was a disagreement as to the degree of degradation between the GC-FID method and the ESI-MS results. GC-FID data indicated $>86 \%$ of the original TiDG had degraded (Table 3.4), while the iDA data from the ESI-MS indicated a $100 \%$ degradation of the washed (neutral) suppressor had occurred. The concentration of the iDA determined by ESI-MS was $3.022 \mathrm{mM}, 101 \%$ of the known concentration, which was calculated by weight. 
Currently, the differences seen between these two methods as to the degree of degradation measured for the washed TiDG have yet to be explained. Chromatograms generated by GC-FID (Figure 3.10) show TiDG remains in the washed samples.

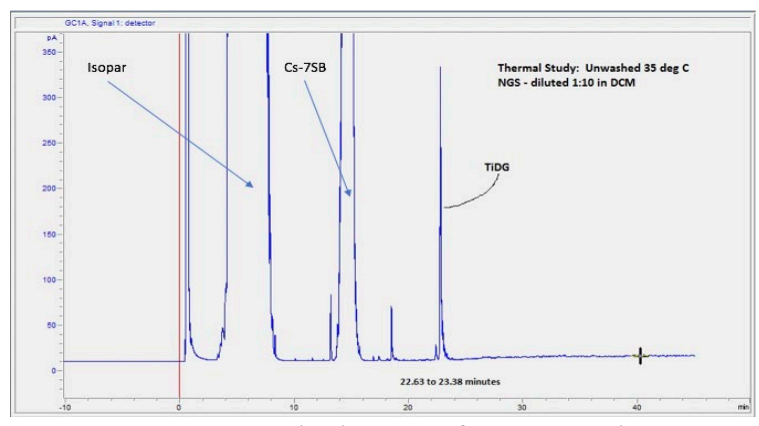

A. Unwashed, $25^{\circ} \mathrm{C}$ for 19 months

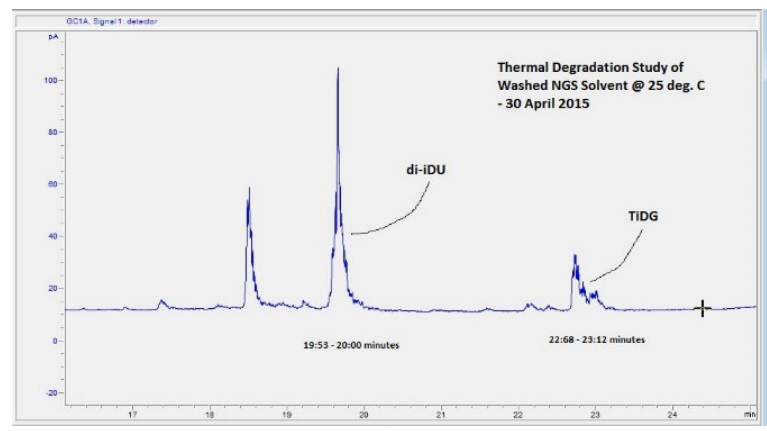

C. Washed, $25^{\circ} \mathrm{C}$ for 19 months

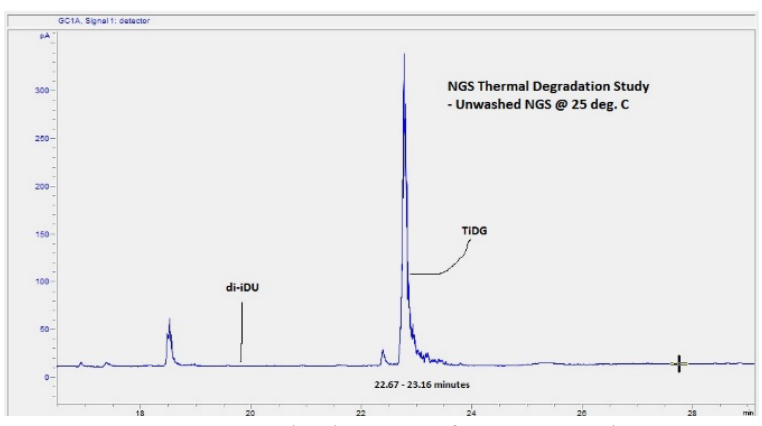

B. Unwashed, $35^{\circ} \mathrm{C}$ for 19 months

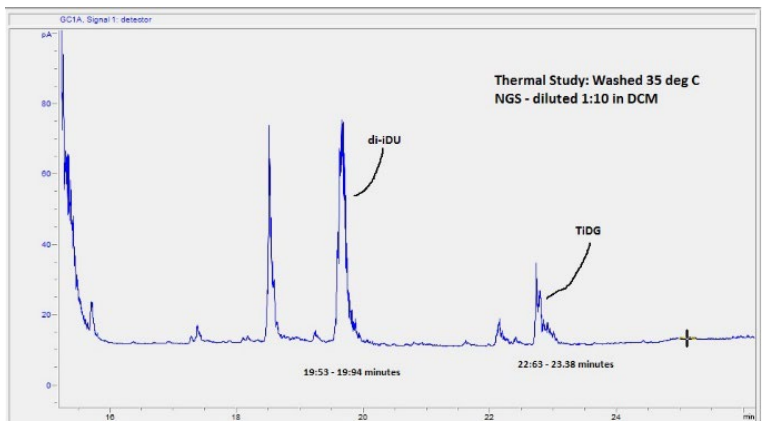

D. Washed, $35^{\circ} \mathrm{C}$ for 19 months

* Unwashed solvent (guanidinium in the protonated form) showed no degradation over the 19-month storage period at $25{ }^{\circ} \mathrm{C}$ or $35^{\circ} \mathrm{C}$. The washed solvent (leaving the guanidinium in the neutral form) was seriously degraded, with only 15-17\% of the original TiDG remaining at the end of the incubation period.

Figure 3.10. Chromatograms Showing CG-FID peaks of TiDG and di-iDU in washed and unwashed NGS Solvent stored at either $25^{\circ} \mathrm{C}$ or $35^{\circ} \mathrm{C}$ for 19 months.

Table 3.4. GC determination of degradation of TiDG in stored* NGS solvent

\begin{tabular}{lccccc} 
Sample name & $\begin{array}{c}\text { di-iDU } \\
\text { ng/ } \mu \mathrm{L}\end{array}$ & $\begin{array}{c}2 \text { di-IDU } \\
(\mathrm{mM})\end{array}$ & $\begin{array}{c}\text { TiDG } \\
\text { ng/ } \mu \mathrm{L}\end{array}$ & $\begin{array}{c}{ }^{2} \text { TiDG } \\
(\mathrm{mM})\end{array}$ & $\begin{array}{c}1 \text { iDA } \\
(\mathrm{mM})\end{array}$ \\
\hline Washed $25^{\circ} \mathrm{C}$ & 901 & 2.64 & 210 & 0.41 & 3.34 \\
Unwashed $25^{\circ} \mathrm{C}$ & ------ & ----- & 1940 & 3.76 & $<0.03$ \\
Washed $35^{\circ} \mathrm{C}$ & 928 & 2.72 & 231 & 0.45 & 2.99 \\
Unwashed $35^{\circ} \mathrm{C}$ & ------- & ------ & 2240 & 4.13 & $<0.03$ \\
\hline
\end{tabular}

* - Solvent stored, uncontacted, for 19 months at temperatures of $25^{\circ} \mathrm{C}$ or $35^{\circ} \mathrm{C}$.

1 - iDA determined by Ben Roach using ESI-MS

2 - TiDG \& di-iDU measured by GC

3 - Higher than starting TiDG levels in unwashed samples indicative of solvent evaporation. 


\section{CONCLUSIONS}

This document details a GC-FID-method for the direct, rapid, and accurate quantification of the NGS solvent guanidine suppressor TiDG and one of its two degradation products, di-isodecylurea. Solvent samples can be fully analyzed by this technique in as little as twenty minutes following their withdrawal from the MCU or SWPF solvent storage tank. The development of this method was mandated by prior studies $^{12,13}$ that inferred the apparent slow thermal degradation of the TiDG suppressor and a corresponding loss of stripping performance when the NGS solvent was contacted with simulated SRS waste for a period of one to three months at $36^{\circ} \mathrm{C}$. Test results suggested that the NGS solvent could perform within acceptable limits for only seven months without replenishing TiDG. ${ }^{12}$

This GC-FID method was validated by successfully determining the concentrations of TiDG and di-iDU in a number of test samples. Following that validation, the testing protocol was used to quantify this suppressor and its urea degradation byproduct in a number of washed and unwashed solvent samples that had been stored at either $25^{\circ} \mathrm{C}$ or $35^{\circ} \mathrm{C}$ for 19 months. In addition, electrospray mass-spectrometry (ESIMS) was used to quantify the iDA degradation product. ${ }^{15}$ Together, the GC-FID (this report) and ESI-MS results ${ }^{15}$ confirmed that virtually no degradation of the unwashed (protonated) TiDG occurred over the 19month storage period at either temperature. However, washed (neutral form) TiDG did undergo considerable degradation at both storage temperatures, although there was some disagreement between the two analytical methods as to the degree of suppressor breakdown.

This slow thermal degradation observed for the TiDG suppressor ${ }^{12,13}$ has prompted the undertaking of a near-term investigation into the effect and fate of the TiDG breakdown products (Moyer, limited communication ${ }^{16}$ ) on the NGS process. Should necessity require a suppressor change, and funding become available, then an additional task will involve the development of a more stable guanidine suppressor. ${ }^{16}$ 


\section{REFERENCES}

1. B. A. Moyer, S. D. Alexandratos, P. V. Bonnesen, G. M. Brown, J. E. Caton, Jr., L. H. Delmau, C. R. Duchemin, T. J. Haverlock, T. G. Levitskaia, M. P. Maskarinec, F. V. Sloop, Jr., and C. L. Stine, Caustic-Side Solvent Extraction Chemical and Physical Properties: Progress in FY 2000 and FY 2001, ORNL/TM-2001/285, Oak Ridge National Laboratory, Oak Ridge, TN, 2002.

2. L. H. Delmau, J. F. Birdwell, Jr., P. V. Bonnesen, L. J. Foote, T. J. Haverlock, L. N. Klatt, D. D. Lee, R. A. Leonard, T. G. Levitskaia, M. P Maskarinec, B. A. Moyer, F. V. Sloop, Jr., and B. A. Tomkins, Caustic-Side Solvent Extraction: Chemical and Physical Properties of the Optimized Solvent, ORNL/TM-2002/190, Oak Ridge National Laboratory, Oak Ridge, Tennessee, October, 2002.

3. B. A. Moyer, J. F. Birdwell, Jr., P. V. Bonnesen and L. H. Delmau, "Use of Macrocycles in NuclearWaste Cleanup: A Real-World Application of a Calixcrown in Technology for the Separation of Cesium," pp. 383-405 in Macrocyclic Chemistry-Current Trends and Future, K. Gloe, Ed., Springer: Dordrecht, 2005.

4. T.B. Peters, A. L. Washington, II, F. F. Fondeur, and S. D. Fink, Supplemental Analyses for Solvent Hold Tank Samples MCU-11-314, MCU-11-315, MCU-11-316, MCU-11-317, MCU-11-318 and, MCU-11-319, SRNL-STI-2011-00591, Savannah River National Laboratory, Aiken SC, September 2011.

5. B. A. Moyer, P. V. Bonnesen, L. H. Delmau, F. V. Sloop, Jr., N. J. Williams, J. F. Birdwell, Jr., D. L. Lee, R. A. Leonard, S. D. Fink, T. B. Peters, and M. W. Geeting, "Development of the Next-Generation Caustic-Side Solvent Extraction (NG-CSSX) Process for Cesium Removal from High-Level Tank Waste-11346", Proceedings Waste Management 2011 Conference, Waste Management Symposia, Tempe, AZ, February 27-March 3, 2011.

6. L. H. Delmau, J. F. Birdwell, Jr., P. V. Bonnesen, C. J. Ladd, B. A. Moyer, E. L. Stoner, D. L. Lee, and F. V. Sloop, Jr., "Next-Generation Caustic-Side Solvent Extraction (NG-CSSX) Process. Proc. International Solvent Extraction Conference ISEC 2011, Santiago, Chile; ed. F. Valenzuela and B. A. Moyer, Santiago, Chile, October 3-7, 2011.

7. B. A. Moyer, J. F. Birdwell, Jr., P. V. Bonnesen, S. H. Bruffey, L. H. Delmau, N. C. Duncan, D. D. Ensor, T. G. Hill, D. L. Lee, A. Rajbanshi, B. D. Roach, P. L. Szczygiel, F. V. Sloop, Jr., E. L. Stoner, and N. J. Williams, Next Generation Solvent Development for Caustic-Side Solvent Extraction of Cesium, ORNL/TM-2014/22, Oak Ridge National Laboratory, Oak Ridge, TN, 2014.

8. P. V. Bonnesen, N. C. Duncan, and A. Rajbanshi, Preparation of 1,3-Dicyclohexyl-2(Isotridecyl)guanidine and 1,3-Dicyclohexyl-2-(Isotridecyl)guanidine Hydrochloride (DCITG and DCITG.HCl, Suppressor for Next Generation CSSX Process Solvent. ORNL-LTR-NGCSSX-007, Oak Ridge National Laboratory, Oak Ridge, TN, April 2011.

9. N. C. Duncan, B. D. Roach, N. J. Williams, P. V. Bonnesen, A. Rajbanshi, and B. A. Moyer, N,N'Dicyclohexyl-N'-Isotridecylguanidine as Suppressor for the Next Generation Caustic-Side Solvent Extraction (NG-CSSX) Process, Sep. Sci. Technol., 47, 2074-2087 (2012); DOI: 10.1080/01496395.2012.697517.

10. B.A. Moyer, L. H. Delmau, N. C. Duncan, D. D. Ensor, T. G. Hill, D. L. Lee, B. D. Roach, F. V. Sloop, 
Jr., and N. J. Williams, Recommended Guanidine Suppressor for the Next-Generation Caustic-Side Solvent Extraction Process; Report ORNL/TM-2012/625, Oak Ridge National Laboratory: Oak Ridge, TN, January 2013.

11. E. Brass, C. Aponte, E. Ketusky, and A. Garrison, "Implementation of Next Generation Solvent in The Caustic-Side Solvent Extraction Process for Increased Removal of Cesium at Savannah River Site," Paper 14266, Proc. Waste Management 2014, Phoenix, AZ Tempe, AZ, Mar. 2-6, 2014.

12. B. D. Roach, N. J. Williams, and B. A. Moyer, Thermal Degradation of the Solvent Employed in the Next-Generation Caustic-Side Solvent Extraction Process and its Effect on the Extraction, Scrubbing, and Stripping of Cesium, Solvent Extraction and Ion Exchange, 33: 576-591, (2015).

13. T. G. Hill, D. Ensor, L. H. Delmau, and B. A. Moyer, Thermal Stability Study of a New Guanidine Suppressor for the Next-Generation Caustic-Side Solvent Extraction Process. Sep. Sci. Technol., 51 (7), 1133-1140 (2016); DOI: 10.1080/01496395.2016.1143509

14. F. V. Sloop, Jr. and B. A. Moyer, Using GC-FID to Quantify the Removal of 4-sec-Butylphenol from NGS Solvent by NaOH, ORNL/TM-2014/444, Oak Ridge National Laboratory, Oak Ridge, TN, 2014.

15. B. D. Roach, Unpublished results, 2015.

16. B. A. Moyer, limited communication white paper, 'Elimination of the risk due to suppressor degradation in the CSSX next generation solvent for the salt waste processing facility, September 2016. 


\section{INTERNAL DISTRIBUTION}
1. F. V. Sloop, Jr.
2. B. A. Moyer
3. R. Custelcean
4. V. Bryantsev
5. S. Jansone-Popova
6. N. J. Williams

7. I. Popovs

8. A. Momen

9. B. Roach

10. ORNL Office of Technical Information and Classification

\section{EXTERNAL DISTRIBUTION}

Earl Brass, Savannah River Remediation, LLC, 241-121H, Room 1, Aiken, SC 29808

Samuel D. Fink, Savannah River National Laboratory, 773-A, Rm. B-112, Aiken, SC 29808

Cliff Conner, Parsons Engineering, 1062 Silver Bluff Rd., Aiken SC 29803

Frank M. Pennebaker, Savannah River National Laboratory, 773-42A, Rm. 146, Aiken, SC 29808

Aaron Washington, Savannah River National Laboratory, 773-42A, Rm. 118, Aiken, SC 29808

Tom Peters, Savannah River National Laboratory, 773-42A Rm. 128, Aiken, SC 29808 